\title{
LA EJECUCIÓN SIN EXEQUÁTUR. REFLEXIONES SOBRE EL REGLAMENTO BRUSELAS I BIS, CAPÍTULO III
}

\author{
Marta ReQueJo IsIDRo \\ Senior Research Fellow \\ Max Planck Institute Luxemburgo
}

SUMARIO: 1. INTRODUCCIÓN.-2. CONSECUENCIAS INMEDIATAS DE LA SUPRESIÓN DEL EXEQUÁTUR.-2.1. Antes de la ejecución.-2.2. Aplicación de medidas cautelares.-3. EJECUCIÓN EN EL REGLAMENTO: CLAVES.-3.1. El certificado.-3.1.1. Pieza central del sistema.-3.1.2. El diseño del modelo: crítica.-3.1.3. El relativo valor del documento.-3.2. La adaptación de las medidas desconocidas.-3.2.1. «Adaptar».-3.2.2. ¿Adaptar sin exequátur?-3.3. Denegación de la ejecución.-3.3.1. Procedimiento. Delegación en el legislador nacional.-3.3.2. Motivos. - 4. LA NECESIDAD DE NUEVOS EQUILIBRIOS Y REPARTOS.-4.1. Ejecutante, ejecutado: a quién beneficia el sistema.-4.2. Sobre el rol de transición del exequátur.-4.3. Oposición a la ejecución por motivos atinentes al fondo del asunto.-5. INTEGRACIÓN. INTERPRETACIÓN EN SU CONTEXTO.-6. LA IMPLEMENTACIÓN DEL REGLAMENTO EN LOS ORDENAMIENTOS NACIONALES.-6.1. Las primeras reacciones nacionales.-6.1.1. Alemania.-6.1.2. Reino Unido e Irlanda.-6.1.3. Polonia.-6.2 El caso español.-6.2.1. La necesidad de intervención legislativa.-6.2.2. La Ley de Cooperación Jurídica Internacional.-7. VALORACIÓN.-7.1. En singular.-7.2. La perspectiva global.

\section{INTRODUCCIÓN}

De conformidad con el art. 66.2 del Reglamento (UE) núm. 1215/2012, relativo a la competencia judicial, el reconocimiento y la ejecución de resoluciones judiciales en materia civil y mercantil, Bruselas I bis, las resoluciones dictadas a raíz de acciones judiciales ejercitadas en o después del 10 de enero de 2015 en materia civil o mercantil serán reconocidas y/o ejecutadas conforme a dicho Reglamento. En este marco la declaración de ejecutividad no es necesaria para ejecutar una decisión fuera de la jurisdicción que la ha 
dictado. El exequátur se suprime y el foco de atención del sistema pasa a ser la ejecución misma.

Facilitar el exequátur ha sido desde muy temprano un objetivo del legislador europeo ${ }^{1}$, que lo ha abordado de manera progresiva. El Convenio de Bruselas de 27 de septiembre de 1968, primero, y luego su sucesor, el Reglamento (CE) núm. 44/2001, de 22 de diciembre de 2000, simplificaban en gran medida el procedimiento de declaración de ejecutividad. El siguiente estadio en la evolución debería ser la completa supresión del exequátur. Incorporado a la agenda política europea desde $1999^{2}$, se refuerza en los siguientes programas (La Haya, Estocolmo), para hacerse realidad en Reglamentos de ámbito material limitado: el Reglamento (CE) núm. 805/2004, de 21 de abril, por el que se establece un título ejecutivo europeo para créditos no impugnados, el Reglamento (CE) núm. 861/2007, de 11 de julio, por el que se establece un proceso europeo de escasa cuantía, el Reglamento (CE) núm. 1896/2006, de 12 de diciembre, por el que se establece un proceso monitorio europeo, y el Reglamento (CE) núm. 4/2009, de 18 de diciembre de 2008, relativo a la competencia, la ley aplicable, el reconocimiento y la ejecución de las resoluciones y la cooperación en materia de obligaciones de alimentos (para los Estados miembros que son partes del Protocolo de La Haya de 2007) ${ }^{3}$.

La supresión del exequátur había sido defendida por la Comisión en su propuesta de refundición del Reglamento Bruselas I ${ }^{4}$. Como es sabido, la misma sólo culminó parcialmente: en el Reglamento Bruselas I bis el exequátur ha desaparecido como etapa procesal intermedia y las decisiones ejecutables en un Estado miembro lo son inmediatamente en los demás. Sin embargo, los motivos que anteriormente se ofrecían para resistir el reconocimiento y el exequátur se mantienen, si bien en tanto que objeciones a la ejecución. De este modo el Reglamento refundido no representa una continuidad en relación con ninguno de los instrumentos citados en el párrafo anterior.

La propuesta de la Comisión había encontrado una fuerte oposición en los círculos académicos. Ahora bien, la mayoría de las críticas se centraban en la desaparición de los motivos para contestar el exequátur, y en particular en la de la cláusula de orden público ${ }^{5}$; se prestó mucha menos atención a las difi-

1 Véase el art. 220 del Tratado de Roma, de 25 de marzo de 1957.

2 Conclusiones del Consejo Europeo de Tempere, de 16 de octubre de 1999.

3 De forma más restringida también el Reglamento (CE) núm. 2201/2003, de 27 de noviembre. Tampoco existe ya exequátur en Reglamentos posteriores al Bruselas I bis: es el caso del Reglamento (UE) núm. 606/2013, sobre el reconocimiento mutuo de medidas de protección en materia civil, o del Reglamento (UE) 655/2014, del Parlamento Europeo y del Consejo, de 15 de mayo, por el que se establece el procedimiento relativo a la orden europea de retención de cuentas a fin de simplificar el cobro transfronterizo de deudas en materia civil y mercantil. En cambio el requisito pervive en el Reglamento (UE) núm. 650/2012, en materia de sucesiones, y en el Reglamento (UE) 2015/848, sobre procedimientos de insolvencia (refundido).

4 Propuesta de Reglamento del Parlamento Europeo y del Consejo relativo a la competencia judicial, el reconocimiento y la ejecución de resoluciones judiciales en materia civil y mercantil (versión refundida), COM (2010) 748 final.

5 Entre otros muchos: Kramberger Skerl, J., «European Public Policy (with an Emphasis on Exequatur Proceedings)», Journal of Private International Law, 2011, pp. 461-490, y ScHAcK, H., «The 
cultades técnicas que podrían aparecer en el marco de la ejecución de la decisión extranjera ${ }^{6}$. En este sentido el Reglamento contiene unas cuantas, pocas, reglas que tendrán un impacto directo sobre el diseño de los procesos locales de ejecución, mientras que para otros aspectos requiere la cooperación del legislador nacional y otros, en fin, no se regulan en el texto ni se encomiendan a nadie. Así, con la supresión del exequátur pasa a primer término la cuestión de la articulación entre las normas europeas y las nacionales, en un contexto presidido por la diversidad de estas últimas ${ }^{7}$. Es discutible que el resultado final sea un paso adelante en la libre circulación de decisiones en Europa, menos costosa en términos de tiempo y dinero.

El presente estudio se centra en un Reglamento que es, por el momento, pieza única en la UE. Los ejes de la observación son dos: por una parte, la interactuación del Reglamento con los sistemas jurídicos nacionales; por otra, su singularidad en el contexto del espacio de libertad, seguridad y justicia. Lo primero se realizará de dos formas: desde una perspectiva general se analizará qué aporta el Reglamento a los sistemas nacionales, y qué requiere de ellos (apdos. 2 a 5); luego, de forma concreta, se verá qué se ha hecho en los Estados miembros hasta el momento como reacción a una y otra cosa $\left(\right.$ apdo. 6) ${ }^{8}$. Acerca de lo segundo hay que decir que no llevaremos a cabo una comparación exhaustiva de los textos europeos en materia de Derecho procesal civil: se trata más bien de ilustrar con los propios desarrollos del trabajo (si se quiere, de manera transversal) rasgos del Reglamento refundido que lo hacen singular.

\footnotetext{
Misguided Abolition of Exequatur Proceedings in the European Union", Festschrift für Tadeusz. Ercinski, Warschau, LexisNexis Polska, 2011, pp. 1345-1358, defendiendo mantener la cláusula de orden público para proteger los valores intrínsecos de la UE. KRAMER, X., «Approaches to Jurisdiction and Foreign Judgments and the International Fight against Corruption», en International Law and the Fight against Corruption, Mededelingen van de Koninklijke Nederlandse Vereniging voor Internationaal Recht, Preadviezen, 139 (Advisory Report for the Dutch Royal Society of International Law), La Haya, Asser Press, 2012, pp. 99-142, esp. p. 132, la cláusula debe conservarse para luchar contra crímenes objeto de condena global, como la corrupción de los funcionarios públicos. KUIPER, J. J., "The Right to a Fair Trial and the Free Movement of Civil Judgments», Croatian Yearbook of European Law \& Policy, vol. 6, 2010, pp. 23-51, aboga por mantener la cláusula para la defensa del orden público del foro.

${ }^{6}$ Véase no obstante LóPEz DE TEJADA, M., La disparition de l'exequatur dans l'espace judiciaire européenne, París, LGDJ, 2013, pp. 285 y ss. ("Les incertitudes de l'insertion»); TImmER, L. J., "Abolition of Exequatur under the Brussels I Regulation: Ill Conceived and Premature?», Journal of Private International Law, 2013, pp. 129-147, esp. p. 136.

7 Curiosamente, con anterioridad la propia Comisión había considerado imposible la supresión del exequátur, entre otros motivos por la divergencia entre las reglas sobre ejecución en los Estados miembros: COM(97) 609 final, 26 de noviembre de 1997, DO, C núm. 33, de 31 de enero de 1998.

8 En relación con España, donde el proceso de adopción de medidas para implementar el Reglamento aún no ha culminado, se hace un ejercicio teórico de implementación a través de las reglas de ejecución vigentes. Para simplificar el punto de referencia son las sentencias firmes de condena de dinero, mientras que en la ejecución provisional sólo aparecerán puntualmente.
} 


\section{CONSECUENCIAS INMEDIATAS DE LA SUPRESIÓN DEL EXEQUÁTUR}

\subsection{Antes de la ejecución}

La resolución que es ejecutable en un Estado miembro lo será en cualquier otro sin necesidad de una declaración de ejecutividad (arts. 39 y 40): lo que no significa que la ejecución, siquiera provisional ${ }^{9}$, sea inmediata. Puesto que serán aplicables a la resolución extranjera las mismas condiciones que a las decisiones nacionales ${ }^{10}$, de entrada hay que estar a lo que dispongan las reglas locales (art. 41.1). En algunos países es precisa una demanda de ejecución, que desencadena un nuevo proceso en sentido propio, incluso con la posibilidad de una audiencia; es el caso de la acción ejecutiva de los arts. 517 y ss. de la Ley de Enjuiciamiento Civil española (LEC). La ejecución se aplaza también allí donde se otorga al deudor un periodo de gracia, como ocurre en España en virtud del art. 548 de la LEC o, a discreción del juez, en Francia (arts. 1.244-1 a 1.244-3 Code Civil). Además, si la ley del foro lo contempla la persona contra la que se dirige la ejecución puede oponerse (bajo ciertas condiciones) a ella ya en un primer estadio, o por la vía de recursos que canalicen defensas procesales o de fondo.

El Reglamento mismo prevé obligaciones aptas para retardar la ejecución -aunque sin indicación de plazos: corresponde al legislador nacional articularlos-, y contempla circunstancias que conllevan tal efecto. Así, la obligación de notificar el certificado del art. 53 a la persona contra quien se solicita la ejecución antes de cualquier medida de ejecución (art. 43.1). La misma persona tiene derecho a solicitar una traducción de la resolución en caso de que su domicilio se halle fuera del Estado de origen, y no cabe adoptar medidas de ejecución hasta que tal traducción se le proporcione (art. 43.2) ${ }^{11}$. Puede contribuir también a aplazar la ejecución lo que dispone el art. 54: si

9 El Reglamento refundido no contiene previsiones sobre ejecución provisional, a diferencia de lo que ocurre por ejemplo en el Reglamento 4/2009, art. 39 (en el contexto de los recursos contra la decisión en cuanto al fondo).

10 Es principio básico del Capítulo III, Sección 2. ${ }^{a}$, el de equivalencia o asimilación de las decisiones de los Estados miembros a efectos de su tratamiento procesal en ejecución. El principio de extensión de efectos aparece igualmente: art. 54. Algún autor habla del «principio de adaptación», en el mismo precepto: NuYTs, A., "Bruxelles I bis: présentation des nouvelles règles sur la compétence et l'exécution des décisions en matière civile et commerciale», en Barnich, L., Englert, H., NuYTS, A. y Jafferali, R., Actualités en Droit International Privé, Bruselas, Bruylant, 2013 pp. 77-134, párr. 2 (a partir de aquí NuYTs, A., 2013a); id. "La refonte du règlement Bruxelles I», Rev. crit. dr. int. pr., 2013, pp. 1-41, párr. 15 (a partir de aquí NuYTs, A., 2013b). A nuestro modo de ver la adaptación no es un principio, sino una necesidad que en el marco del art. 54 debe ser satisfecha a la luz del principio de extensión de efectos.

11 El Reglamento prevé la posibilidad de solicitar traducciones o transliteraciones de documentos en otros lugares a los fines de la ejecución por parte de la autoridad competente (art. 42), y/o de la parte interesada (art. 54). No se indica si en estos casos caben en el ínterin medidas de ejecución, pero lo presumible es que no. La traducción es necesaria para que la autoridad conozca el contenido de la resolución o del certificado (o la medida extranjera cuyo equivalente ha de buscarse en el propio ordenamiento, art. 54), y por tanto qué es lo que hay que ejecutar, y es lo que permite la defensa de la parte contra la que se solicita la ejecución. 
la decisión extranjera contiene una medida u orden desconocida en el Estado miembro requerido la misma deberá ser adaptada buscando su equivalente funcional en el ordenamiento del foro. Sin duda tal adaptación requiere tiempo, ya que es probable que sea preciso explicar la medida extranjera, su naturaleza y efectos para identificar algo similar en el foro. Cualquiera de las partes puede además impugnar la adaptación (art. 54.2).

\subsection{Aplicación de medidas cautelares}

A tenor del art. 40, toda resolución con fuerza ejecutiva conllevará la facultad de aplicar las medidas cautelares previstas en la legislación del Estado miembro requerido. Son medidas del art. 40 los embargos preventivos, sin realización de los bienes ${ }^{12}$; la información sobre un embargo inminente ${ }^{13} \mathrm{y}$ las medidas para localizar bienes del deudor ${ }^{14}$. A partir del 17 de enero de 2017, en el ámbito de aplicación correspondiente, deberá añadirse la orden europea de retención del Reglamento (UE) núm. 655/2014, de 15 de mayo (con las medidas que la acompañan y, al respecto, véase el art. 14 sobre la obtención de información sobre cuentas).

Conviene detenerse en el alcance de la remisión al Derecho nacional en este punto. A priori la ley del Estado miembro requerido determina tanto las medidas cautelares a adoptar como las condiciones exigidas para ello. No es así, en cambio, si el art. 40 se interpreta a la luz de su antecedente, el art. 47 del Reglamento Bruselas $\mathrm{I}^{15}$, como sugiere el Considerando 34 del Reglamento. Más abajo aludiremos con carácter general a los límites de la continuidad (con la jurisprudencia previa) en la interpretación de los textos ${ }^{16}$; podemos afirmarla ahora, pese a que la equivalencia no consta en la tabla al final del Reglamento. No es seguro, sin embargo, si el modelo del art. 40 es el primer o el segundo apartado del art. 47, lo que no es irrelevante. Las condiciones

12 Landgericht Bonn, de 4 de marzo de 2003, RIW, 2003, p. 388. Sobre una freezing order como medida cautelar en el marco del art. 47 del Reglamento Bruselas I, Banco Nacional de Comercio Exterior SNC v. Empresa de Telecomunicaciones de Cuba SA [2007] EWCA Civ 662, [2007] I.L.Pr. 51; e infra, nota al pie núm. 17.

13 Por ejemplo el § 845 ZPO, "Schon vor der Pfändung kann der Gläubiger auf Grund eines vollstreckbaren Schuldtitels durch den Gerichtsvollzieher dem Drittschuldner und dem Schuldner die Benachrichtigung, dass die Pfändung bevorstehe, zustellen lassen mit der Aufforderung an den Drittschuldner, nicht an den Schuldner zu zahlen, und mit der Aufforderung an den Schuldner, sich jeder Verfügung über die Forderung, insbesondere ihrer Einziehung, zu enthalten. Der Gerichtsvollzieher hat die Benachrichtigung mit den Aufforderungen selbst anzufertigen, wenn er von dem Gläubiger hierzu ausdrücklich beauftragt worden ist. An Stelle einer an den Schuldner im Ausland zu bewirkenden Zustellung erfolgt die Zustellung durch Aufgabe zur Post».

14 Por ejemplo los arts. 551.3.2 y 554 de la LEC española.

15 Que también reproducen otros instrumentos, como el art. 54 del Reglamento (UE) núm. 650/2012. A su vez, el art. 47.1 sigue el modelo del art. 1445 Code Judiciaire belga. Disposiciones similares existen en otros países, como Luxemburgo y Francia. El equivalente al art. 47.3 resultaría ahora de la suma de los arts. 39 y 44, con las variaciones originadas en la supresión del exequátur y la introducción de la solicitud de denegación de la ejecución ex art. 45.

16 Apartado 5. 
de las medidas cautelares en el primer supuesto (esto es, existe un título ejecutivo extranjero, pero aún no la declaración de ejecutividad en el foro) son las propias del ordenamiento del foro. En cambio cabría proyectar sobre el segundo supuesto (esto es, ya hay declaración de ejecutividad) la decisión del TJ en el as. 119/84 ${ }^{17}$, recaída en el marco del art. 39 del Convenio de Bruselas (esto es, cuando se ha otorgado el exequátur y mientras dure el plazo para recurrirlo o se resuelve el recurso contra el mismo). En esta decisión el TJ excluyó supeditar las medidas cautelares a exigencias derivadas del Derecho local, aunque condicionó su respuesta como sigue (apdo. 21): «La cuestión de si una u otra disposición del Derecho procesal interno del Tribunal requerido es aplicable a las medidas cautelares adoptadas en virtud del art. 39, depende del contenido de cada disposición nacional y de su compatibilidad con los principios establecidos por el artículo citado». En el Reglamento Bruselas I bis la desaparición del exequátur y con él, de la relevancia de la diferencia entre una fase previa a él y las posteriores, apunta a este último escenario, y por tanto a la idea de que no es posible condicionar el art. 40 a requisitos locales que pongan en riesgo la efectividad de la regla comunitaria ${ }^{18}$. La aplicación de las medidas cautelares previa a la ejecución, en consecuencia, se complica: primero, porque el tratamiento es diferente para los casos domésticos y los transnacionales cuando el Estado de origen sea miembro de la UE. Segundo, porque en tal supuesto habrá que identificar, entre las condiciones exigibles para otorgar la medida, las que son compatibles con las reglas comunitarias y las que no.

\section{EJECUCIÓN EN EL REGLAMENTO: CLAVES}

A tenor del art. 41 del Reglamento Bruselas I bis el procedimiento de ejecución de las decisiones extranjeras se regirá por la ley del Estado requerido y la ejecución se llevará a cabo en las mismas condiciones que para las resoluciones nacionales. Ahora bien, el propio artículo introduce una reserva: "Sin perjuicio de lo dispuesto en la presente sección», refiriéndose a la Sección 2. ${ }^{a}$ del Capítulo III. Esta, conjuntamente con las disposiciones comunes de la Sección 4. ${ }^{a}$, sienta reglas con impacto directo en la ejecución de las decisiones extranjeras. Algunas de ellas son muy detalladas y no dejan margen -o muy poco- al legislador nacional y a las variaciones locales: así, acerca de los documentos que deben acompañar la solicitud de ejecución. Otras, en cambio, requieren la intervención del legislador nacional, y en consecuencia

17 ECLI:EU:C:1985:388. En España la decisión ha sido utilizada en el marco del art. 47.3 del Reglamento Bruselas I para estimar el recurso contra la imposición de fianza a la parte ejecutante cuando, otorgado el exequátur, la parte contraria formuló oposición contra el auto: Auto de la AP de Barcelona (Sección 15. ${ }^{a}$ ), de 4 de marzo de 2004, AC/2004/1550.

18 Gascón Inchausti, F., «La reconnaissance et l'exécution des décisions dans le règlement Bruxelles I bis», en GuINCHARD, E. (ed.), Le nouveau règlement Bruxelles I bis, Bruselas, Bruylant, 2014 pp. $205-$ 247, párr. 25; Kramer, X., "Art. 40», en Dickinson, A. y Lein, E. (eds.), The Brussels I Regulation Recast, Oxford, OUP, 2015, núm. 13.195, con más referencias. 
abren la puerta a soluciones divergentes en la UE: por ejemplo, el art. 43 indica sólo que la notificación debe hacerse «antes de la primera medida de ejecución» pero no especifica cuánto «antes» (el Considerando 32 y su alusión a una «antelación razonable» no es realmente una ayuda).

De las reglas sobre ejecución del Reglamento destacan las relativas al certificado previsto en el art. 53: a la necesidad de adaptar las órdenes o medidas contenidas en la resolución original, si son desconocidas en el Estado miembro requerido (art. 54); y a la posibilidad de solicitar la denegación de la ejecución sobre la base de argumentos del propio Reglamento (arts. 45 y ss.), con posibles consecuencias sobre el curso de la ejecución misma (art. 44.1) ${ }^{19}$.

\subsection{El certificado}

\subsubsection{Pieza central del sistema}

El Reglamento Bruselas I bis dispone en su art. 42 qué documentación debe acompañar la solicitud de ejecución, desplazando cualquier otra condición al respecto en la legislación nacional (por ejemplo, en España, el art. 956 de la LEC de 1881, que exige indirectamente traducir la ejecutoria). No es precisa la declaración de ejecutividad: basta la presentación de la decisión extranjera y el certificado a que se refiere el art. 53.

El certificado del Reglamento refundido difiere notablemente del mismo documento en el Reglamento previo, Reglamento (CE) 44/2001: ahora es obligatorio (no lo era antes, en el art. 55 del Reglamento Bruselas I); el órgano para emitirlo es el órgano jurisdiccional de origen, y no cualquier otra autoridad (art. 54 del Reglamento Bruselas I) ${ }^{20}$; su contenido es altamente detallado, conforme al modelo del anexo I (frente al anexo V del Reglamento Bruselas I); y hay que notificar el documento a la persona contra la cual se insta la ejecución antes de cualquier medida ejecutiva, conforme al art. 43, a fin de proteger sus derechos de defensa. Incluso elementos que reproducen el Reglamento anterior son susceptibles de una interpretación distinta: esto es probablemente lo que ocurre con la legitimación para solicitar el documento pese a que, como en el art. 54 del Reglamento previo, se ofrece a «cualquier parte interesada» (art. 53). La noción está por definir; su comprensión debe ser única en la UE, lo que aboga a favor de una definición autónoma. En este contexto se ha sugerido que la interpretación debe ser amplia y adaptada

19 Igualmente nueva, aunque presente en algún instrumento previo [p. ej., art. 21.3 del Reglamento (CE) núm. 867/2007], es la regla que exime al solicitante de ejecución de domicilio postal en el Estado requerido, así como de la necesidad de representación salvo que la misma sea obligatoria por razones distintas de la nacionalidad o el domicilio: art. 41.3.

20 Conviene recordar que la misma exigencia aparece en otros instrumentos, lo que no ha impedido que el legislador nacional encomiende la tarea al personal del tribunal y no al juez mismo. Así en Francia, en el contexto del Reglamento sobre el título ejecutivo europeo, art. 509-1 del CPC (greffier en chef). Véase también infra, apartado 6.1.1, el caso de Alemania. 
al sustancial cambio que representa la supresión del exequátur ${ }^{21}$; sobre ello volveremos más abajo (infra apdo. 5). En todo caso la expresión debe abarcar a quien figure en la decisión judicial como acreedor, y a quienes le hayan sucedido en tal posición y así lo acrediten (cuando el hecho no resulte de la resolución misma) ${ }^{22}$.

A la luz de lo anterior se comprende que el certificado es pieza clave del sistema; una vocación de importancia singular que no ha pasado desapercibida en la doctrina ${ }^{23}$. Cada vez más la confianza recíproca se materializa -e incluso se sustenta- en un papel: por eso es llamativo que el legislador europeo no haya cuidado más determinados aspectos del documento.

\subsubsection{Diseño del modelo: crítica}

Los reproches al Reglamento en lo relativo al certificado tienen dos vertientes: se critica por un lado el diseño del formulario, y por otro la falta de regulación del procedimiento para solicitar y expedir el documento.

$\mathrm{El}$ anexo I ofrece desde luego un formulario muy completo, en el que sin embargo faltan menciones relevantes: así, la de si la decisión a ejecutar es recurrible o no ${ }^{24}$. También se debe denunciar la complejidad en la manera de reflejar algunos datos: los intereses legales, por ejemplo, se indican por medio de referencia a la ley aplicable; si ésta es extranjera en relación con el lugar de ejecución a la autoridad competente no le resultará ni sencillo ni rápido hacer el cálculo.

En relación con el trámite de obtención del certificado son cuestiones abiertas la relativa a los plazos para solicitarlo y emitirlo; la admisibilidad de tasas por su expedición; la de si existe recurso contra su otorgamiento o denegación. Alguna de estas ausencias son explicables: la relación de directa dependencia entre el certificado y la ejecución, y el hecho de que el plazo para pedir ésta se regule en cada Estado miembro, puede justificar la falta de solución uniforme en cuanto al plazo de solicitud del documento. Por el contrario sí habría cabido indicar una solución única en cuanto al tiempo límite para expedirlo - al menos para el caso en que se pide por separado en relación con la demanda $-{ }^{25}$. La falta de mención a una tasa de expedición, o a mecanismos de rectificación del certificado por errores materiales o para su

21 Fitchen, J., «Art. 53», en Dickinson, A. y Lein, E. (eds.), The Brussels I Regulation Recast, Oxford, OUP, 2015, núm. 13.477.

22 Por ejemplo Auto del TS, de 18 de octubre de 2005, JUR/2005/270947, sobre legitimación para solicitar la ejecución por cesión de derechos del demandante.

${ }^{23}$ Pohl, M., «Die Neufassung der EuGVVO- im Spannungsfeld zwischen Vertrauen und Kontrolle», IPRax, 2013, pp. 109-114, esp. p. 113.

24 Puede ocurrir que se trate de una mención obligatoria en la propia decisión, como ocurre en España (art. 208 de la LEC), pero puede que no. Tendría sentido que lo fuera en el certificado.

${ }^{25}$ Infra, apartado 6.2.2, la solución en la LEC tras la Ley 29/2015, de 30 de julio, de cooperación jurídica internacional en materia civil, $B O E$ núm. 182, de 31 de julio. 
revocación, que sí están en otros textos ${ }^{26}$, es también más difícil de explicar; y, sobre todo, es difícil decidir si significa la exclusión radical de estos aspectos, o sólo que el legislador europeo se ha desentendido de ellos, dejando el campo libre al nacional ${ }^{27}$.

Tampoco tiene una respuesta clara la pregunta sobre si el certificado forma parte del título ejecutivo ${ }^{28}$. Su naturaleza obligatoria apoya la respuesta afirmativa. Sin embargo, ello implicaría consecuencias difícilmente aceptables en el marco legal y de política legislativa de la UE: la inexactitud del certificado podría fundamentar una defensa contra la ejecución al Estado requerido, no prevista en el Reglamento. Esta posibilidad había sido discutida en la doctrina española en relación con el título ejecutivo europeo, y rechazada en virtud de la existencia del art. 10 en el Reglamento correspondiente ${ }^{29}$; ahora bien, una norma similar falta en el nuevo Reglamento.

\subsubsection{El relativo valor del documento}

El recurso a formularios normalizados y certificados es ya una práctica común en la UE, con el fin de agilizar los trámites transfronterizos y abaratarlos; son útiles para la libre circulación de decisiones. Ahora bien, la rapidez no prevalece sobre otros objetivos. La progresión en la libre circulación de decisiones en el seno de la UE ha dependido siempre de la capacidad para garantizar un determinado nivel de calidad en la administración de la justicia por parte de los Estados miembros. A la vista de los diferentes textos (Reglamentos) es evidente que el nivel de calidad no es el mismo en todos los ámbitos: la confianza mutua posee un distinto alcance en el ámbito sucesorio, por ejemplo, y en materia de restitución de menores secuestrados. El valor de los certificados previstos en cada caso varía en función de ello.

En el marco del Reglamento (CE) núm. 44/2001 el TJ ha admitido la prueba contra lo dispuesto en el certificado en el Estado requerido como una consecuencia del sistema de doble control que pervive en el Reglamento. Ello, porque «limitar el alcance de la facultad de examen de la que dispone en esta fase el juez del Estado miembro requerido por el mero motivo de que se ha presentado una certificación equivaldría a privar al control que este mismo juez debe efectuar de todo efecto útil, y, por tanto, a impedir la realización del objetivo consistente en garantizar el respeto del derecho de defensa establecido por dicho Reglamento» ${ }^{30}$. A la pregunta sobre si la solución vale para el Reglamento refundido la respuesta es probablemente

\footnotetext{
26 Por ejemplo, el art. 25 del Reglamento (CE) núm. 1896/2006 establece una regla sobre tasas en relación con el conjunto del proceso. El art. 10 del Reglamento (CE) núm. 805/2004 regula la rectificación de errores materiales del certificado.

27 Sobre este punto en general véase el apartado 5.

28 Entiende que sí GASCón InCHAUSTI, F., párr. 10; añade en cambio que las traducciones no lo son (op. cit., nota 18, nota al pie núm. 24).

29 Ramos Romeu, F., El título ejecutivo europeo, Cizur Menor, Civitas, 2006, p. 126.

30 As. C-169/10, ECLI:EU: C:2012:531, núm. 45.
} 
afirmativa ${ }^{31}$. Ciertamente, en él se exige que el certificado sea expedido por un órgano jurisdiccional. A priori tal exigencia, que se explica en la mayor complejidad del documento ${ }^{32}$, debería servir para dotarle de un valor añadido en la línea del art. 42 del Reglamento (CE) núm. 2201/2003. Sin embargo, tal como señaló el TJ en el párrafo reproducido, ello no sería compatible con el sistema de doble control que el Reglamento mantiene: el mismo devendría impracticable. Aparte de ello la falta de previsión de recurso contra el otorgamiento del certificado, o para su rectificación en origen, imponen esta misma solución: tanto el Reglamento sobre el título ejecutivo europeo, art. 10, como el Reglamento (CE) núm. 2201/2003 — para las decisiones que suprimen el exequátur, art. 43- prevén estas posibilidades en el Estado de origen, en consonancia con la idea de un sistema de «ventanilla única» ${ }^{33} \mathrm{o}$ control único, a efectuar en dicho Estado; que no existan en el Reglamento Bruselas I bis, justifica que deba quedar abierta la posibilidad de contestar el certificado en el Estado requerido.

Incompleto, user-unfriendly, y (posiblemente) contestable, el nuevo certificado, que quiere ser uno de los avances esenciales del Reglamento refundido, se queda en definitiva a medio camino.

\subsection{La adaptación de las medidas desconocidas}

\subsection{1. "Adaptar»}

Una novedad (al menos en la letra) del Reglamento refundido es la obligación impuesta al Estado requerido en relación con las medidas u órdenes contenidas en la decisión extranjera que sean desconocidas en el foro; conforme al art. 54 habrá que adaptarlas dentro de lo posible, buscando en el ordenamiento propio órdenes o medidas similares con efectos equivalentes.

La obligación de adaptar las medidas responde por una parte a una necesidad práctica: es difícil imaginar cómo se implementará una orden extraña al sistema en que se pretende ejecutar, si éste no dispone de los útiles necesarios al respecto. Por otra parte, así se evita que el resultado de esa dificultad práctica se traduzca en la simple denegación de la ejecución de la medida. A la vista de estos datos sorprende que el Reglamento no exija que la adaptación sea de oficio.

31 Opina que la cuestión está abierta Fitchen, J., op. cit., nota 21, núm. 13.481.

32 Beraudo, J. P., «Regards sur le nouveau règlement Bruxelles I sur la compétence judiciaire, la reconnaissance et l'exécution des décisions en matière civile et commerciale», JDI, 2013, núm. 3 (versión electrónica), núm. 41: "Il faut donc espérer que les juridictions seront dotées, en temps utile, du personnel apte à accomplir cette tâche supplémentaire qui impose de savoir lire et comprendre un procès-verbal de signification, l'en-tête ainsi que le dispositif d'un jugement, et de rédiger la synthèse présentant la brève description de l'objet du litige et de la décision rendue par la juridiction».

33 Tomamos prestada la expresión de HEss, B., «The Influence of the ECHR on the European Law of Civil Procedure», ponencia presentada en Madrid, 21 de mayo de 2015, pendiente de publicación en el AEDIPr. 
La adaptación es, en línea de principio, una actividad corriente en el ámbito de las relaciones jurídico privadas transfronterizas, que ponen en relación ordenamientos jurídicos diferentes constantemente. Ello no significa que adaptar sea sencillo; de hecho, ni siquiera está siempre claro en qué consiste $^{34}$; en ocasiones es dudoso hasta lo que hay que adaptar ${ }^{35}$. En el contexto del Reglamento refundido la adaptación requiere una comparación entre la medida extranjera, por definición desconocida, y las potenciales equivalentes en el Derecho nacional; exige, pues, conocimientos jurídicos y pericia por parte del adaptador. Éste deberá cuidar también de que al buscar la equivalencia no otorga a la medida original más efectos que los que tiene en el ordenamiento del primer Estado. ¿Podría, en cambio, darle menos? El alcance exacto del principio de extensión es difícil de determinar a la luz de afirmaciones como ésta del TJ en el as. C-420/07: «A este respecto, aunque, en principio, el reconocimiento debe producir el efecto de atribuir a las resoluciones la autoridad y la eficacia con que cuentan en el Estado miembro en el que han sido dictadas (...), no hay razones para dar a una resolución extranjera, en el momento de su ejecución, derechos que no tiene en el Estado miembro de origen $[. .$.$] o efectos que no produciría una resolución del mismo tipo dic-$ tada directamente en el Estado miembro requerido» ${ }^{36}$. La cuestión vuelve a ser de nuevo qué significa «adaptar», y los límites, no siempre claros, entre esta operación y otras proscritas - como la revisión en cuanto al fondo-. Es significativo que la obligación de adaptación, que consta también de forma expresa en el art. 11 del Reglamento (UE) núm. 606/2013, se limite en este texto a los elementos fácticos de la decisión original.

\subsection{2. ¿Adaptar sin exequátur?}

La necesidad de adaptaciones ya había sido aludida por el TJ antes del Reglamento refundido ${ }^{37}$. Ahora bien, entonces la tarea se desarrollaba en el marco del exequátur. De hecho, en algunos ordenamientos la adaptación de instituciones o medidas desconocidas se define como una de las funciones clá-

34 ¿Es adaptación en el sentido del art. 54 la operación de fijar el montante de una condena ilíquida? Repárese en que de serlo cabría a cualquiera de las partes recurrir conforme al art. 54.2 (en otro caso puede que también, pero al amparo de otra norma). Véase en este sentido la sentencia del Tribunal Supremo italiano de 7 de agosto de 2002, n. 11921, Anglo Venezuelan Real Estate and Agricultural Development Limited c. Zanussi, Guido Altinex ASA, Giurisprudenza Italiana, 2003, pp. 649 y ss., sobre el reconocimiento de una decisión inglesa que había condenado al demandado a los gastos del juicio del demandante, sin fijar el montante; la determinación del mismo se había dejado en manos de la autoridad competente en el Reino Unido (el Taxing Master). El tribunal señaló que a pesar de que en el Derecho italiano son indivisibles la condena en costas y su liquidación la decisión era apta para desplegar efectos en Italia, porque a los fines del reconocimiento podía ser asimilada a la condanna generica del Derecho italiano.

35 Véase infra, apartado 6.2.2., sobre este punto en la LEC tras la modificación operada por la Ley 29/2015, de 30 de julio, de cooperación jurídica internacional en materia civil (adaptación de la resolución misma).

36 ECLI:EU:C:2009:271, núm. 66.

37 As. C-235/09, ECLI:EU:C:2011:238. 
sicas del exequátur ${ }^{38}$; en la Propuesta de la Comisión quedaba limitada a los supuestos excepcionales en que aún sería necesario el exequátur ${ }^{39}$. En línea de principio esto supone que un órgano jurisdiccional se ocupa de la adaptación. El Reglamento no toma partido a este respecto: «Corresponde a cada Estado miembro determinar cómo proceder a tal adaptación y quién debe realizarla», reza el Considerando núm. 28; y a diferencia de lo que sucede con la expedición del certificado (art. 53) no se exige aquí la intervención de un juez o tribunal. La solución se explica, probablemente, en las diferencias entre los Estados miembros en torno a la autoridad competente para la ejecución -quiénes son, cuál es su estatuto profesional, para qué actividades son para las que están capacitadas, cuál es su responsabilidad, o cómo se organizan-, que es, lógicamente, la primera en que se piensa para adaptar de cara a poder ejecutar. Ahora bien, no es seguro que cualquier operador jurídico local esté preparado para la tarea de adaptar; y a día de hoy los apoyos con que se cuenta para conocer y comprender un ordenamiento extranjero son escasos ${ }^{40}$.

La supresión del exequátur con la consecuente asunción de tareas de adaptación por parte de las autoridades de la ejecución había suscitado ya la crítica. Muy directa, señalaba la AG J. Kokkot que «una ejecución fuera del Estado miembro en el que se dictó la resolución sin que se haya declarado la fuerza ejecutiva de esta última entrañaría asimismo considerables problemas prácticos. Los órganos ejecutivos nacionales apenas podrían evaluar la resolución extranjera que les ha sido presentada y, en particular, tampoco podrían examinar las condiciones de la ejecutoriedad de la resolución ni determinar la naturaleza y el alcance de la ejecución que deben llevar a cabo ${ }^{41}$. En la doctrina también se subraya la conveniencia de la intervención de un juez a la hora de adaptar: en Francia o Bélgica, por ejemplo, donde presumiblemente la tarea se encomiende al huissier de justice, los autores sugieren que en caso de duda tanto el huissier como las partes estén autorizadas para acudir a un juez ${ }^{42}$. En Alemania se reprocha al legislador nacional la solución

38 Nuyts, A., 2013a, op. cit., nota 10, párr. 3; Bureau, D. y Muir-Watt, H., Droit International Privé, t. I, París, 3. a ed., PUF, 2014, párr. 298. No es el caso en España: pero aquí la ejecución posterior al exequátur exige un proceso judicial en el que tiene lugar la adaptación de la medida.

39 Art. 66 de la Propuesta.

40 Gascón Inchausti, F., op. cit., nota 18, párr. 24, entiende que corresponde a la parte ejecutante proponer la adaptación; ello aportará indicaciones a seguir por el órgano que la efectúe, aunque desde luego no está obligado a seguirlas. El TJUE ha señalado alguna pauta: véase el as. C-235/09, ECLI:EU:C:2011:238. La Red Judicial Europea debería servir como apoyo en este punto. El Considerando 16 del Reglamento sobre sucesiones, que es un caso específico de adaptación, contempla lo siguiente: «A fin de determinar el derecho real equivalente más cercano del Derecho nacional, se podrá entrar en contacto con las autoridades o personas competentes del Estado cuya ley se haya aplicado a la sucesión para obtener más información sobre la naturaleza y los efectos de ese derecho. A estos efectos, podría recurrirse a las redes existentes en el ámbito de la cooperación judicial en materia civil y mercantil, así como a cualesquiera otros medios disponibles que faciliten la comprensión de la ley extranjera».

41 Conclusiones al as. C-92/12 PPU, ECLI:EU:C:2012:177, núm. 74. También TimmER, L. J., op. cit., nota 6, p. 140 .

42 Van Boxstael, J. L., «De Bruxelles I à Bruxelles Ibis», Journal des Tribunaux, 2015, pp. 105-108, párr. 80. Podría tratarse del juge des saisies (NuYTs, A., 2013a, op. cit., nota 10, párr. 3), o del de primera instancia (VAN BoXstael, J. L., op. cit., nota 42, párr. 80). 
incorporada al § 1114 ZPO, conforme a la cual la adaptación recae sobre el Gerichtsvollzieher y el Rechtspfleger; a juicio de los autores estos funcionarios son capaces de llevar a cabo tareas simples, como el cálculo de intereses progresivos, pero es dudoso que puedan afrontar con éxito situaciones más complejas que requieran disponer de un bagaje de conocimientos jurídicos y de un idioma extranjero ${ }^{43}$. En España la adaptación será llevada a cabo por el juez de la ejecución o por el secretario judicial, lo que en general debería garantizar una base jurídica sólida ${ }^{44}$.

Finalmente, hasta el mismo Reglamento capitula: el art. 54 prevé la recurribilidad de la adaptación por cualquiera de las partes e implica en este estadio a un órgano jurisdiccional.

\subsection{Denegación de la ejecución}

\subsubsection{Procedimiento. Delegación en el legislador nacional}

Conforme al art. 45 cualquier parte interesada puede oponerse a la ejecución sobre la base de causas contempladas por el propio Reglamento - que son, en gran medida ${ }^{45}$, las mismas que bajo el anterior régimen permitían objetar al exequátur- ${ }^{46}$. Con esta regla el Reglamento refundido abre la puerta al legislador de la UE en un ámbito, el de la ejecución, hasta ahora reservado al legislador nacional, salvo contadas y bastante perfiladas excepciones.

Lo cierto es que el Reglamento aporta poco al diseño del procedimiento de denegación de la ejecución. Razones similares a las que explican que el Reglamento no concrete la autoridad que adaptará las medidas de ejecución desconocidas en el foro ${ }^{47}$ justifican su reserva en relación con el procedimiento: es la consecuencia lógica de la supresión del exequátur y la migración de los motivos de oposición al estadio de la ejecución ${ }^{48}$. Sin embargo, ni la opción ni la explicación convencen totalmente. Lo primero, por los resultados que provoca: una potencial diversidad de soluciones nacionales. Lo segundo, porque en instrumentos anteriores al presente, como el Reglamento (CE) núm. 4/2009, sí se han incluido soluciones uniformes: por ejem-

43 Schlosser, P. y Hess, B., «Art. 54», en EU-Zivilprozessrecht, EuGVVO, EuMahnVO, EuBagVO, EuZVO, EuBVO Kommentar, Munich, C. H. Beck, 2015, marg. 4.

44 Infra, apartado 6.2.

45 El art. 45 agrupa en una sola disposición el contenido de los arts. 34 y 35 del Reglamento 44/2001. La unidad no parece tener mayores consecuencias. Más entidad poseen los cambios en la extensión del control de la competencia del juez de origen en los litigios que involucran a una parte débil, con la limitación explícita a los casos en que es ésta la demandada, y la inclusión de los contratos de trabajo [art. 45.1.e)].

46 Cuestión distinta es si conservan la misma naturaleza; ligado a ello, si cabe mantener para ellos la interpretación recaída hasta el momento a propósito de los arts. 34 y 35 del Reglamento Bruselas I. Véase infra, apartado 5.

47 Supra, apartado 3.2.

48 Gascón Inchausti, F., op. cit., nota 18, párr. 44. 
plo, para el cómputo de plazos (Considerando 41); incluso se ha establecido un supuesto de fuerza ejecutiva provisional (art. 39); no se ve por qué no en éste.

Sea como fuere, lo cierto es que es el legislador europeo involucra ampliamente al nacional en este aspecto, en dos sentidos. Por una parte, le encomienda una tarea con doble alcance: el procedimiento de la Sección 3. ${ }^{\mathrm{a}}$, Subsección 2. ${ }^{a}$, ha de valer tanto para la solicitud de denegación de ejecución como para declarar que no concurren motivos de denegación del reconocimiento del art. 45 (art. 36.2 del Reglamento) ${ }^{49}$. Por otra parte, corresponde a cada Estado miembro decidir el iter procedimental y concretar las reglas de textura abierta que contempla el Reglamento ${ }^{50}$; para este fin hay pocas pautas comunes, algunas de ellas sólo implícitas. Por ejemplo, el hecho de que el procedimiento elegido haya de servir a un doble fin, como acabamos de ver, restringe de facto el margen de acción del legislador local.

El Considerando 30 ofrece una indicación acerca del procedimiento al pronunciarse a favor de acumular todos los motivos - los previstos en el ordenamiento nacional, y los del art. 45- para resistir la ejecución. No concreta, sin embargo, si ello debe ocurrir en el marco general vigente en cada ordenamiento para la oposición a la ejecución, o en el contexto del procedimiento que (eventualmente) se diseñe ex novo para tramitar una solicitud de denegación de ejecución al amparo de los arts. 45 y ss. del Reglamento. La opción se deja en manos del legislador local.

El articulado, por su parte, hace una remisión general al Derecho nacional con la típica reserva «En la medida en que no esté recogido en el presente Reglamento» (art. 47): pero el Reglamento, como se ha dicho, es escueto. De la letra del art. 46 se infiere que la solicitud tendente a que la ejecución se deniegue es posible una vez se haya instado la misma (la ejecución); no se admite, por tanto, con carácter preventivo. En la sección se determinan los documentos que debe aportar el solicitante (art. 47), y se obliga a lo siguiente: debe existir una posibilidad de recurso, en tanto que otra ulterior no es necesaria (arts. 47.1, 49, 50); hay que resolver «sin demora» (art. 48); y el órgano jurisdiccional está facultado para suspender el procedimiento para la denegación, en cualquiera de sus estadios, si la decisión en causa está siendo objeto de recurso en el Estado de origen o el plazo para recurrirla no ha finalizado (art. 51). En consecuencia, la cuestión sobre cómo implementar procesalmente la posibilidad de resistencia ofrecida a la persona contra quien se solicita la ejecución, con base en los motivos del art. 45, queda pendiente.

49 En el seno del Reglamento la relación entre las dos operaciones —reconocimiento y ejecución- no va más lejos; no se aborda el significado de denegación del reconocimiento en el marco de una solicitud ulterior para la denegación de la ejecución, o viceversa. BERAUDO, J. P., op. cit., nota 32, núm. 47; HAU, W. (LiNKE/HAU) Internationales Zivilverfahrensrecht, 6. ${ }^{\mathrm{a}}$ ed., Colonia, Otto Schmidt, 2015, párr. 14.24.

50 Es el caso del art. 43, sumado al Considerando 32: no impone un plazo concreto para notificar el certificado, pero sí exige que ello se haga con «antelación razonable». Algo similar ocurre en el art. 48: la decisión sobre la solicitud de denegación de la ejecución debe adoptarse «sin demora». 
Cabe imaginar dos soluciones: intentar canalizar la oposición en el seno de procedimientos ya existentes, diseñados para resistir la ejecución de decisiones domésticas; o crear un nuevo cuadro procedimental independiente, probablemente en la línea del extinto exequátur. Esta última es la solución por la que por el momento se está optando ${ }^{51}$; seguramente es la respuesta que más facilita dotar de doble funcionalidad al proceso (que ha de servir, como vimos, para denegar la ejecución y para constatar la ausencia de motivos de no reconocimiento). Los nuevos procedimientos nacionales para la denegación del exequátur se conciben como compartimentos estancos —el Considerando 30 ha caído en saco roto-.

\subsubsection{Motivos}

El TJ ha insistido en el pasado en mantener separados los estadios de exequátur y ejecución: en el asunto 145/86 indica que una parte que no ha recurrido el exequátur en el momento previsto para ello conforme al Convenio de Bruselas, art. 36, no podrá «alegar en la fase de ejecución de la resolución una razón válida que hubiera podido invocar en el marco de dicho recurso»; la solución debe ser aplicada de oficio ${ }^{52}$. Recíprocamente, en el asunto C-267/97 señala que no caben objeciones a la ejecución en el momento del exequátur ${ }^{53}$. La postura del TJ había dado lugar a reacciones de diverso signo en función del Estado miembro considerado: en España viene a corroborar una situación (teóricamente) consolidada en el nivel nacional después de un largo periodo de discusión y de jurisprudencia contestable ${ }^{54}$; en otros países, en cambio, se percibe como una oportunidad perdida de potenciar la eficacia del sistema ${ }^{55}$. En Alemania la crítica suma consideraciones dogmáticas en relación con causas que se entiende se dirigen contra la decisión nacional sobre exequátur, y no contra el título extranjero ${ }^{56}$.

51 Infra, apartado 6.

52 ECLI:EU:C:1988:61, núm. 34.

53 ECLI:EU:C:1999:213.

54 La confusión entre reconocimiento y exequátur, por una parte, y exequátur y ejecución, por otra, ha sido una constante de la jurisprudencia española denunciada prontamente por la doctrina (véase ya Remiro Brotóns, A., Ejecución de sentencias extranjeras en España, Madrid, Tecnos, 1974, p. 305; CoRtés Domínguez, V., Derecho procesal civil internacional, Madrid, EDERSA, 1981, pp. 162-163), y que se ha corregido sólo hasta cierto punto: véase ejemplos y comentario de MARTínEz SANTOS, A., «Régimen procesal del reconocimiento y el exequátur en el Reglamento 44/2001, de 22 de diciembre de 2000: algunos problemas prácticos de su aplicación en España», en DE LA OlIVA SANTOS, A. y CALDERóN Cuadrado, M. P. (dirs.), La armonización del Derecho procesal tras el Tratado de Lisboa, Cizur Menor, Thomson Reuters Aranzadi, 2012, pp. 253-284, esp. pp. 270-277.

55 López de TeJADA, M., op. cit., nota 6, párrs. 350 y ss.

56 Hess, B., «Europäischer Vollstreckungstitel und nationale Vollstreckungsgegenklage», IPRax, 2004, pp. 493-494, esp. p. 494, con más referencias; BiтTMAnN, D. C., «Die Zulässigkeit materiellrechtlicher Einwendungen gegen einen Europäischen Vollstreckungstitel im Vollstreckungsstaat», IPRax, 2015, pp. 129-134, esp. p. 134. En Francia se ha planteado la misma cuestión en relación con el délai de grâce: la respuesta depende de la opinión acerca de si tal plazo se refiere a la deuda declarada en el Estado de origen, o si modifica los efectos de la decisión de exequátur. Véase MuIR WATT, H., "Note Cour d'Appel de Paris (1er Ch.), 9 mars 1995», Rev. crit. dr. int. pr., 1995, pp. 735-741, esp. p. 735. 
La jurisprudencia del TJ no vale en el Reglamento refundido: los motivos del art. 45 son ahora causas para objetar la ejecución. No hay, por tanto, diferencia conceptual con otros motivos previstos al mismo efecto en los ordenamientos nacionales; conforme al art. 41 todos se suman. Ahora bien, las causas de oposición previstas a nivel local no se aceptan de forma incondicionada: depende de que sean compatibles con las causas que enumera el propio Reglamento refundido. Qué implica exactamente el requisito no es seguro. El hecho de que se haga referencia sólo a la compatibilidad de los ordenamientos de los Estados miembros con el art. 45 no es relevante, a nuestro juicio: no es verosímil que el legislador europeo haya querido limitar así el deber genérico de respetar el efecto útil del Reglamento. Resulta llamativo, en todo caso, que no se haga una referencia expresa a la prohibición de revisión en cuanto al fondo del art. 52: las razones más probables de incompatibilidad entre un ordenamiento nacional y el sistema del Reglamento se encuentran en las posibilidades que ofrezca el primero de esgrimir objeciones sustantivas contra la ejecución —lo que se acerca demasiado a una révision du fond — ${ }^{57}$.

\section{LA NECESIDAD DE NUEVOS EQUILIBRIOS Y REPARTOS}

\subsection{Ejecutante, ejecutado: a quién beneficia el sistema}

¿Cómo afecta el Reglamento refundido a las posiciones respectivas del acreedor y deudor?

Por lo que se refiere al primero, a priori las perspectivas del vencedor en el litigio de origen de poder ejecutar rápidamente la sentencia en otro país mejoran con el Reglamento. Recíprocamente, empeoran las del deudor o persona contra la que se pide la ejecución. El paulatino avance de la libertad de circulación de decisiones en Europa permite concluir que la posición del deudor en un escenario transfronterizo se ha transformado: de encontrarse cómodamente protegido por las fronteras pasa a ver su patrimonio expuesto en un área geográfica muy extensa.

En realidad, la supresión del exequátur obliga a buscar nuevas fórmulas para el equilibrio entre las partes. Señala el Considerando 29 que «la ejecución directa en el Estado miembro requerido de una resolución dictada en otro Estado miembro sin la declaración de fuerza ejecutiva no debe comprometer el respeto de los derechos de la defensa». Así se explica que el Reglamento acompañe la ejecutabilidad inmediata de la decisión extranjera de la facultad de pedir la denegación de ejecución por los motivos del art. 45. También, la facultad que se otorga al ejecutado de pedir la traducción de la decisión extranjera en el supuesto en que el Estado de su domicilio no coincida con el de origen (art. 43); la norma se inspira en el art. 8 del Reglamento sobre notifi-

57 Bittmann, D. C., Von Exequatur zur qualifizierten Klausererteilungsverfahren, Baden-Baden, Nomos, 2008, pp. 194-208. Véase también infra, apartado 4.3. 
cación. Merece la pena recordar que hasta que la traducción se proporcione al solicitante caben las medidas cautelares, pero no de ejecución (art. 43.3).

La preocupación por los derechos de defensa del deudor no es discutible. Cosa distinta es la impresión que produce el Reglamento de que sus disposiciones resultarán en la práctica en la mejora de la posición del ejecutado, y en detrimento del acreedor ${ }^{58}$. La legitimación para alegar los motivos que contempla el art. 45, por ejemplo, es (y tiene que ser) ahora más amplia que bajo el régimen precedente; ello, porque antes operaban contra la solicitud de exequátur y ahora se abren a la persona contra quien se solicita la ejecución, coincida o no con la parte demandada en el proceso de fondo (única legitimada pasiva, en cambio, en el trámite del exequátur).

Hay otras reglas aptas para retardar ${ }^{59}$, comprometer, o dificultar la ejecución. De entrada, la posición del acreedor se apuntala por la vía de eliminar formalidades y costes. Sin embargo, el art. 43 autoriza al deudor a solicitar la traducción de la resolución (ciertamente bajo algunas condiciones), y corresponde al acreedor proporcionársela soportando el gasto ${ }^{60}-\mathrm{al}$ menos en principio- ${ }^{61}$. La carga de contestar la ejecutabilidad de la decisión con base en los motivos del art. 45 recae sobre la persona contra quien se solicita la ejecución, y en este sentido es un gravamen para ella; no obstante, al mismo tiempo puede funcionar como una estrategia para ralentizar la ejecución, jugando con la difusa frontera entre el ejercicio legítimo de los derechos y su abuso. En opinión de la doctrina el riesgo de que el deudor aproveche la oportunidad es mayor cuanta menos experiencia posea la autoridad competente para decidir sobre este punto ${ }^{62}$.

Otras previsiones que no están concebidas pensando específicamente en proteger al ejecutado pueden terminar volviéndose en contra del ejecutante. Un ejemplo es la complejidad en la manera de reflejar datos el certificado: los intereses legales se indican por medio de referencia a la ley aplicable; si ésta es extranjera en relación con el lugar de ejecución a la autoridad competente no le resultará sencillo ni rápido hacer el cálculo. Otro ejemplo es el caso del recurso previsto en el art. 54 contra la adaptación de las medidas u órdenes desconocidas. Es cierto que la posibilidad se ofrece a ambas partes, pero es de esperar que en la mayoría de los casos la propuesta de adaptación provenga de la que está interesada en ejecutar ${ }^{63}$ : la contestación, por tanto, de la otra parte.

58 La idea de que el Reglamento es parcial a favor del deudor aparece (y es criticada) en la literatura: HEss, B., «Urteilsfreizügigkeit nach der VO Brüssel-Ia: beschleunigt oder ausgebremst?», en Festschrift für P. Gottwald zum 70. Geburtstag, Munich, C. H. Beck, 2014, pp. 273-281, esp. p. 278, «Die Bevorzugung des Schuldners im Vollstreckungstaat».

59 Supra, apartado 2.1 .

60 De acuerdo con el Reglamento las traducciones deben ser realizadas por personas cualificadas (art. 57.3); reglas más tolerantes, como nuestro art. 144 de la LEC, no son aplicables.

${ }^{61}$ El legislador nacional debe determinar quién corre con los costes en última instancia, pero tal como está redactado el Reglamento de entrada corresponden al ejecutante.

${ }^{62}$ Hess, B., op. cit., nota 58, p. 280.

63 Supra, nota al pie núm. 40. 
Finalmente, es preciso recordar que los riesgos o amenazas que pesan sobre el deudor y sus derechos, y de los que debe ocuparse el Reglamento, son los ligados al carácter transfronterizo del supuesto, y no otros; respecto a ellos la posición del legislador europeo debe ser neutra y permitir que se realicen las opciones de política legislativa preferidas por el legislador nacional ${ }^{64}$. Es por este motivo por lo que el Reglamento no convence en este punto. El requisito de notificación del certificado al ejecutado antes de cualquier medida de ejecución, impuesto por el art. 43, elimina el efecto sorpresa: el deudor, avisado así de que se pretende la ejecución forzosa contra él en otro país (aunque no se identifique en cuál), podrá tratar de ocultar su patrimonio ${ }^{65}$. Cabe preguntarse por qué razón el deudor merece ser protegido en una forma que pone en peligro las posibilidades de cobro del acreedor; o, dicho de otra manera, es dudoso que el carácter transfronterizo de la situación justifique que el deudor, que lo es ya por sentencia, conozca de antemano la intención de la parte vencedora de intentar la ejecución contra él en otro país. En todo caso: corresponde al legislador nacional decidir el momento de la notificación y por tanto el margen de maniobra de que dispone el deudor; y debe hacerlo procurando el equilibrio en la posición de la otra parte.

\subsection{Sobre el rol de transición del exequátur}

Como dijimos al comienzo de este estudio la Propuesta de la Comisión de 2010 tendente a suprimir el exequátur encontró la oposición de los círculos académicos. La mayor parte de la crítica se centraba en la desaparición de los motivos de oposición al exequátur, en particular la cláusula de orden público. Sin embargo, abolir el exequátur da lugar a otras consecuencias tal vez menos visibles, pero igualmente relevantes en la práctica. A alguna ya hemos hecho referencia ${ }^{66}$. Otras se comprenden fácilmente: en los litigios transfronterizos se produce con frecuencia una ruptura entre los estadios procesales de cognición y de ejecución, intrínsecamente relacionados en el seno de cada sistema singular. Un ejemplo simple: en muchos sistemas legales la obligatoriedad de la representación legal en la ejecución depende de que fuera o no obligatoria en la fase previa; véase, por ejemplo, el art. 539 de la LEC. En un litigio transfronterizo surge la pregunta sobre qué ordenamiento (el de origen o el de la ejecución) es competente para decidir sobre la vinculación entre los dos estadios; en caso de que la misma exista, todavía hay que determinar si la representación en la ejecución depende de que fuera precisa en el proceso declarativo efectivamente desarrollado en origen, o de que hubiera

64 Por ejemplo, en el sentido de relativizar la protección del deudor ya condenado atenuando la contradicción y la igualdad de armas, en el entendimiento de que debe ser menor que en la fase cognitiva del proceso precisamente porque ya hay condena.

${ }^{65}$ GASCÓn INCHAUSTI, F., op. cit., nota 18, párr. 32, subraya el impacto negativo de la disposición en la dinámica de la ejecución. CunIBERTI, G., «La réforme du règlement Bruxelles I», Droit et Procédures, 2013 , pp. 26-33, esp. p. 27, alude a la incoherencia entre la regla y el objetivo europeo de libre circulación de decisiones.

66 Véase el apartado 3.2.2. 
sido necesaria en el proceso declarativo de haberse sustanciado en el Estado de ejecución.

El exequátur, como paso intermedio entre el Estado de origen de una decisión y el requerido, opera (idealmente) como puente entre ambos, reconectando los dos estadios mencionados y facilitando el tránsito de un sistema a otro: por un lado homologando la resolución extranjera, es decir, equiparándola a una nacional; por otro, al proveer un escenario y un tiempo para la adaptación si ésta hace falta ${ }^{67}$. En ausencia de una declaración de ejecutividad las dificultades ligadas a la ruptura antes referida reaparecen. Un ejemplo es el de qué día tomar como referente para calcular el plazo para pedir la ejecución: sin un auto (o equivalente) de exequátur no hay un dies a $q u o$ nacional para hacerlo ${ }^{68}$. Dudas similares se producen en torno al délai de grâce que algunos ordenamientos conceden al deudor para que cumpla voluntariamente la sentencia.

Por virtud de su función de homologación el exequátur ayuda a establecer una línea divisoria entre las cuestiones que caen en el ámbito de aplicación de la lex fori, y las que corresponden a la lex causae, ley del Estado miembro de origen; una separación que no necesariamente sigue la pauta utilizada para decidir lo que corresponde decidir a cada una de las jurisdicciones en juego (Estado de origen y Estado de la ejecución). La cuestión se relaciona con la del alcance y relación entre principios sistémicos fundamentales de la UE, como son el de equivalencia o asimilación, y el de extensión de efectos. Mientras que la delimitación teórica entre ellos es clara (el primero se refiere a los aspectos procesales de la ejecución, el segundo a las consecuencias materiales de la fuerza ejecutoria del título) ${ }^{69}$, su implementación en la práctica no es sencilla. El exequátur, por supuesto, no resolvía todas las dudas, pero ayudaba a arrojar cierta luz en la materia. Como consecuencia de abolir el exequátur incertidumbres que ya existían bajo el régimen del Reglamento Bruselas I serán experimentadas ahora con más fuerza ${ }^{70}$. De nuevo un ejemplo es la prescripción ${ }^{71}$. La aplicabilidad de las reglas en vigor en el Estado de origen de la decisión tiene sentido, por cuanto la cuestión está ligada al carácter ejecutable del título. Sin embargo, también la lex fori tiene algo que decir, por cuanto como consecuencia del exequátur se dota a la decisión extranjera de ejecutividad en el foro: es por ello por lo que la segunda solución ha prevalecido en algunos países ${ }^{72}$. La supresión del exequátur lleva consi-

67 Timmer, L. J., op. cit., nota 6, pp. 137-138; y nota precedente.

68 En numerosos sistemas es ese el día para el cálculo; no en España, donde de acuerdo con la Sentencia del TS, de 16 de octubre de 2014, ES:TS:2014:4838, el momento relevante es el de la adquisición del carácter definitivo por la resolución extranjera en el Estado de origen, y la solicitud de declaración de ejecutividad forma parte del procedimiento de ejecución mismo a los efectos de la prescripción o la caducidad (sic) de la acción ejecutiva.

69 Sobre el alcance del principio de extensión de efectos supra, apartado 3.2.

70 López de TeJADA, M., op. cit., nota 6, párrs. 362 y ss.

71 El periodo de gracia es otro ejemplo: Ramos RomeU, F., op. cit., nota 29, p. 122.

72 Sentencia de la Cour de Cassation Civ. 1re, de 19 de marzo de 1991, Rev. crit. dr. int. pr., 1992, p. 108, nota ANCEL, B.; Sentencia del TS, de 16 de octubre de 2014, ES:TS:2014:4838. 
go en el Reglamento (CE) núm. 4/2009 (art. 21.2) la no-decisión entre una y otra ley; ambas están llamadas a regir este punto, prevaleciendo en cada caso la que establezca un periodo más largo (a favor, por tanto, del acreedor de alimentos, lo que se explica en el contexto particular del Reglamento en cuestión). En el marco del Reglamento refundido hay que preguntarse si la desaparición del exequátur conlleva la de la posibilidad de oponerse a la ejecución sobre la base de la prescripción según la lex fori. La cuestión debe ser tratada con cautela a la vista de las diferencias entre los ordenamientos de los Estados miembros en cuanto a los límites temporales para solicitar la ejecución (doce años en Irlanda; cinco en España; treinta en Alemania).

\subsection{Oposición a la ejecución por motivos atinentes al fondo del asunto}

En materia de oposición a la ejecución es frecuente que se distinga entre motivos procesales y de fondo, o sustantivos, que afectan a la existencia o al contenido de la obligación de las partes documentada en el título. En España la alegación de motivos de fondo abre un incidente declarativo en el proceso de ejecución. Aparte de ello, y a modo de compensación al carácter tasado de los motivos de oposición en sede de ejecución, se prevé un proceso declarativo independiente donde discutir otras causas basadas en circunstancias nacidas una vez precluidas las posibilidades de alegación en juicio (art. 564 de la LEC). A la luz de la naturaleza de estos motivos y similares en otros ordenamientos ${ }^{73}$ es pertinente preguntarse dónde hay que discutirlos en casos transfronterizos: si en el Estado de origen o en el Estado requerido. En el Reglamento (CE) núm. 1896/2006 la cuestión se aborda en el art. 22.2 en relación con el pago: a instancia del demandado, el órgano jurisdiccional competente del Estado miembro de ejecución denegará ésta cuando el demandado haya pagado al demandante el importe fijado en el requerimiento europeo de pago, y en la medida en que lo haya efectuado. En principio la solución es distinta en el Reglamento sobre el título ejecutivo europeo: la supresión del exequátur se acompaña del encargo al Estado de origen de todos los controles sobre la decisión que va a circular; ahora bien, la práctica se ha desviado en la dirección opuesta ${ }^{74}$. El TJ, por su parte, indicó obiter dicta en el as. C-139/10 que la ejecución de una resolución judicial en modo alguno elimina su carácter ejecutorio, pero que «ese motivo puede estar sujeto al examen del órgano jurisdiccional de ejecución del Estado miembro requerido», ya que "según reiterada jurisprudencia, una vez que una resolución queda integrada en el ordenamiento jurídico del Estado miembro requerido, las normas nacionales

\footnotetext{
73 Otro ejemplo típico es el § 767 ZPO (Vollstreckungsabwehrklage). Sobre otras similares en otros sistemas legales BITTMANN, D. C., op. cit., nota 57, pp. 182-194.

74 OLG Colonia, de 21 de noviembre de 2014, IPRax, 2015, p. 158. La decisión trata de las objeciones materiales del § 767 ZPO a la ejecución en Alemania de una transacción homologada en Austria. Para el OLG las objeciones deben ser discutidas y decididas por el juez de la ejecución, y no ante el juez de origen. Crítico, BitTmann, D. C., op. cit., nota 57, p. 129.
} 
de este último Estado relativas a la ejecución se aplican de la misma manera que a las resoluciones adoptadas por los órganos jurisdiccionales ${ }^{75}$. La pregunta remitida por el órgano nacional era más amplia, cubriendo además del cumplimiento cualquier otro motivo surgido después de ser adoptada la resolución a ejecutar.

La falta de distinción entre tipos de motivos en el art. 41.2 del Reglamento Bruselas I bis, así como en el Considerando núm. 30, apuntan a que se sigue en él la misma pauta. Ahora bien, si esta solución se impone creará un efecto disuasorio en la iniciativa de la «exportación» de decisiones: supone que una discusión que afecta al fondo de asunto se podría llegar a replantear hasta en 27 Estados miembros - al menos, en todos aquellos diferentes al de origen en donde se pretenda la ejecución de la resolución-. El resultado no parece compatible con los objetivos principales de la UE en el espacio de libertad, seguridad y justicia ${ }^{76}$. Es pertinente, por tanto, sugerir que la interpretación del art. 41 vaya en el otro sentido.

\section{INTEGRACIÓN. INTERPRETACIÓN EN SU CONTEXTO}

El Reglamento refundido es una joint-venture: el legislador nacional está llamado a cooperar en la implementación del texto, en muchas ocasiones con gran libertad y amplio alcance. La pregunta es cómo reaccionar ante aspectos que el Reglamento no resuelve, pero tampoco traslada para su regulación al otro legislador.

No hay una sola respuesta. En su jurisprudencia a propósito del margen de acción de las autoridades nacionales en los Estados miembros para completar los textos comunes el TJ ofrece como pauta el que exista o no armonización en el instrumento comunitario considerado: así se ha pronunciado, por ejemplo, a propósito del art. 7 del Reglamento (CE) núm. 1896/2006, en el as. C-215/11 ${ }^{77}$. Importa también la fórmula elegida para llamar al legislador nacional. El art. 26 del mismo Reglamento señala que «todas las cuestiones procesales no tratadas expresamente en el presente Reglamento se regi-

\footnotetext{
75 ECLI:EU:C:2011:653, núm. 40.

76 Hess, B., op. cit., nota 58, pp. 279-280. Al mismo tiempo es imaginable que otros autores aprobarán este aspecto del Reglamento, por cuanto ya se han expresado en ese sentido en relación con el título ejecutivo europeo: Bittmann, D. C., op. cit., nota 56, p. 130. En España Garcimartín AlfÉrez, F. J., El título ejecutivo europeo, Cizur Menor, Civitas, 2006, párr. 124, nota 12, a favor de una distinción entre las objeciones que se basan en hechos extintivos sobrevenidos, y objeciones que afectarían la validez o la eficacia del título ab initio. La propuesta no elimina la pluralidad de procedimientos, por cuanto los hechos nuevos se discutirían en el/los Estado/s de la ejecución, y la decisión adoptada en este sentido tendría un alcance territorial limitado. La jurisprudencia española no ofrece ejemplos que apunten claramente en un sentido u otro; sí se encuentra enunciada de forma abstracta la idea de que los motivos, aún sobrevenidos, que impiden la ejecución, no son alegables contra el exequátur pero sí contra la ejecución, lo que en principio sustenta la idea de que habrá que oponerlos en todos y cada uno de los países en que la misma se solicite: véase por ejemplo el Auto del TS, de 4 de marzo de 2003, JUR/2003/87950. Insistimos, en todo caso, en que no cabe hablar de una toma de postura concluyente.

77 ECLI:EU:C:2012:794.
} 
rán por el Derecho nacional», y a la luz de la decisión del TJ en los asuntos C-119/13 y C-120/13 ${ }^{78}$ es posible sostener que el adverbio «expresamente» es relevante. Proyectando estos criterios sobre el Reglamento refundido cabe afirmar que el legislador nacional posee margen para aportar soluciones a aspectos que el Reglamento no toca - siempre dentro del respeto a los principios de efecto útil, y en su caso, de efectividad y equivalencia- ${ }^{79}$. Ahora bien, que lo haga puede generar nuevas preguntas: por ejemplo, si en el Estado miembro de origen se admite un recurso para rectificar errores materiales del certificado, ¿dejaría de ser posible contestarlo en el Estado requerido? ${ }^{80}$.

La integración es también una cuestión de interpretación del Reglamento. En principio las pautas a seguir son las comunes. Recuerda el Considerando 34 que donde se reproducen soluciones ya vigentes en el sistema anterior ${ }^{81}$ cabrá presumir que las interpretaciones realizadas por el TJUE se mantienen: por ejemplo, para determinar qué es «ejecutable» valen las aportaciones del TJ en el asunto C-267/97, así como en el as. C-139/10 ${ }^{82}$. Es interesante resaltar que la tabla de equivalencias con el Reglamento Bruselas I no es fiable, por cuanto no las refleja siempre debidamente: por ejemplo, en lo relativo al art. 40, equiparable al art. 47 del Reglamento Bruselas I.

La puerta debe quedar abierta, no obstante, a interpretaciones diferentes cuando a pesar de la identidad literal entre el nuevo y el antiguo Reglamento el contexto en el uso de una expresión varíe. Es lícito, por ejemplo, cuestionar la continuidad en la interpretación de reglas que conservan la misma dicción literal pero cuya función (¿naturaleza?) cambia, como sucede con los motivos enunciados en el actual art. 45: anteriormente empleados como obstáculos a la declaración de ejecutividad en el Estado requerido, ahora pasan a ser causas de denegación de la ejecución en sentido estricto ${ }^{83}$. De forma

78 ECLI:EU:C:2014:2144, núm. 45.

79 El «efecto útil» se predica del propio texto de la UE que es complementado por el legislador nacional. Los otros dos principios operan enmarcando la autonomía procesal de los Estados miembros en el contexto de la implementación de derechos conferidos al individuo por el propio ordenamiento de la UE —véase por ejemplo el as. C-415/11, ECLI:EU:C:2013:164, núm. 50—: «A falta de armonización de los mecanismos nacionales de ejecución forzosa, las modalidades de aplicación de los motivos de oposición admitidos en el marco de un procedimiento de ejecución hipotecaria y de las facultades conferidas al juez que conozca del proceso declarativo, competente para analizar la legitimidad de las cláusulas contractuales en virtud de las que se estableció el título ejecutivo, forman parte del ordenamiento jurídico interno de cada Estado miembro en virtud del principio de autonomía procesal de los Estados miembros, a condición, sin embargo, de que no sean menos favorables que las que rigen situaciones similares de carácter interno (principio de equivalencia) y de que no hagan imposible en la práctica o excesivamente difícil el ejercicio de los derechos que confiere a los consumidores el ordenamiento jurídico de la Unión (principio de efectividad)».

${ }^{80}$ Tales preguntas no serán frecuentes; por ahora los legisladores nacionales arriesgan poco. Véase no obstante el § 1116 ZPO alemana, que va más allá del supuesto de suspensión de la fuerza ejecutiva de la decisión en origen a los efectos del art. 51.

${ }^{81}$ No se mencionan los Reglamentos previos que suprimen el exequátur; en principio la solución es la misma.

82 ECLI:EU:C:1999:213, el primero; ECLI:EU:C:2011:653, el segundo.

${ }^{83}$ Los motivos del art. 45, de apreciarse, impedirán la ejecución en el Estado requerido —no en el de origen, y tampoco en cualquier otro Estado miembro-. Ello no significa que sean automáticamente asimilables a los otros obstáculos a la ejecución en sentido propio, lo que justifica (sumado a 
implícita o explícita los autores aceptan la aplicabilidad de la jurisprudencia recaída a propósito de los arts. 34 y 35 del Reglamento Bruselas I ${ }^{84}$.

Otro ejemplo surge al hilo de lo que sea "cualquier parte interesada» (art. 53 del Reglamento Bruselas I bis, art. 54 del Reglamento Bruselas I). Para ella se ha propuesto una interpretación amplia y adaptada al sustancial cambio que representa la supresión del exequátur ${ }^{85}$. La proposición tiene sentido en relación con aquellos ordenamientos donde exista una diferencia entre la legitimación activa para solicitar el exequátur y la ejecución, siendo ésta más amplia: y es que la relación íntima entre exequátur y ejecución no implica necesariamente que la legitimación para pedir la segunda (o padecerla, como ejecutado) se comunique al proceso previo ${ }^{86}$.

La tarea de interpretación de los elementos nuevos en el Reglamento cuenta también con los trabajos previos ${ }^{87} \mathrm{y}$ con las explicaciones que provee el propio Reglamento en el Preámbulo. En la línea de lo que ocurre en otros instrumentos recientes de la UE, como el nuevo Reglamento sobre insolvencia, los Considerandos del Reglamento (UE) núm. 1215/2012 han ganado en extensión y detalle, lo que conduce a preguntarse si poseen un valor interpretativo superior a otros criterios hermenéuticos; ello se traduciría en la necesidad de una mayor argumentación por parte de quien sostenga una interpretación distinta. La cuestión es discutida.

\section{LA IMPLEMENTACIÓN DEL REGLAMENTO EN LOS ORDENAMIENTOS NACIONALES}

\subsection{Las primeras reacciones nacionales}

La necesidad de modificar las reglas nacionales para adecuarlas al Reglamento, o de adaptar otras nuevas, se hizo evidente muy pronto para los Estados miembros. Algunos introdujeron las modificaciones que estimaron pertinentes ya antes del 10 de enero de 2015: es el caso de los Países Bajos ${ }^{88}$,

\footnotetext{
la necesidad de respetar las pautas que indica el Reglamento mismo) la oportunidad de articular un procedimiento distinto para encauzar su alegación por la persona contra quien se solicita la ejecución. Véase infra apartado 6.2, el caso español.

${ }^{84}$ Fitchen, J., «Art. 45», en Dickinson, A. y Lein, E., (eds.), The Brussels I Regulation Recast, Oxford, OUP, 2015, núms. 13.555 y ss.; GASCON InCHAUSTI, F., op. cit., nota 18, párr. 42.

${ }_{85}$ Supra apartado 3.1.

${ }^{86}$ Véase en este sentido, en relación con la diferencia en la legitimación pasiva para uno y otro proceso, los Autos de la AP de Málaga, de 22 de junio de 2000, JUR/2000/283925; de 20 de septiembre, JUR/2001/75705; de 18 de octubre de 2000, n. 260/2000, JUR/2001/44012; de 18 de octubre de 2000, n. 270/2000, JUR/2001/108636.

${ }^{87}$ Es muy ilustrativo en este sentido el análisis que se lleva a cabo en el Capítulo 13 del libro The Brussels I Regulation Recast, Oxford, OUP, 2015, explicando pormenorizadamente los cambios entre los documentos de las diferentes instituciones implicadas en el proceso legislativo.

${ }^{88}$ La regulación holandesa, de 22 de enero de 2014, puede consultarse aquí: https://zoek.officielebekendmakingen.nl/dossier/33676/stb-2014-40?resultIndex $=2 \&$ sorttype $=1 \&$ sortorder $=4$. A nuestro conocimiento no existe traducción de la misma.
} 
Alemania, el Reino Unido, Irlanda y Polonia. Otros, como Luxemburgo ${ }^{89}$ y España ${ }^{90}$, están en estos momentos en el proceso de cambio. Finalmente, en otros no parece haber aún iniciativa legislativa tendente a complementar el texto de la $\mathrm{UE}^{91}$.

\subsubsection{Alemania}

En Alemania el Reglamento se implementa mediante modificaciones a normas en vigor, a través de la Gesetz zur Durchführung der Verordnung (EU) Nr. 1215/2012 sowie zur Änderung sonstiger Vorschriften, de 8 de julio de $2014^{92}$. La ley añade disposiciones a la ZPO (§ 1110 a § 1117) especificando la autoridad —el Rechtspfleger — a cargo de expedir el certificado (§ 1110). A través de un reenvío a otras normas de la misma ZPO se establece el procedimiento para la expedición (con audiencia al deudor o sin ella: § 1111, sec. 1), y para impugnarla (§ 1111, sec. 2). El art. 39 del Reglamento se refleja en el § 1112, que elimina la Vollstreckungsklausel que convierte las decisiones extranjeras en ejecutivas en Alemania. El § 1114 encomienda la adaptación de las medidas extranjeras desconocidas al Gerichtsvollzieher y el Rechtspfleger, recordando que cabe recurrir su decisión. El § 1115 se ocupa de la solicitud de denegación de reconocimiento o ejecución de la resolución extranjera: indica qué tribunal es competente (competencia territorial y funcional), desarrolla aspectos procedimentales (motivación de la decisión; necesidad de audiencia), y los efectos sobre la ejecución de la decisión. El efecto potencial de la suspensión de la fuerza ejecutiva en origen sobre su ejecución en Alemania se contempla en el § 1116, que de hecho va más allá de lo dispuesto en el Reglamento por cuanto incluye el supuesto de limitación de la fuerza ejecutiva, al que el Reglamento no alude. Finalmente, el § 1117 responde, en forma afirmativa, a la cuestión sobre si cabe alegar en Alemania, en el estadio de la ejecución, objeciones sustantivas basadas en motivos que surgen con posterioridad al último momento en que cabría invocarlos en el proceso de fondo. El tribunal competente en este sentido coincide con el mismo del que cabe solicitar la denegación de la ejecución conforme al § 1115.

El hecho de que el legislador alemán haya reaccionado tan rápidamente abriendo caminos para la aplicación del Reglamento es loable. Cosa distinta es que las soluciones sean totalmente convincentes: ya hay críticas de la

89 En Luxemburgo la implementación del Reglamento ha tenido lugar por virtud de la Lo 1 avril 2015 relative à la mise en application du règlement (CE) núm. 1215/2012.

90 España realizó en tiempo la comunicación a que se refiere el art. 75 del Reglamento refundido: véase https://e-justice.europa.eu/content_brussels_i_regulation_recast-350-es-es.do?member $=1$. Infra, apartado 6.2, sobre la necesidad de otras acciones para facilitar la aplicación del Reglamento en España.

91 Es por el momento el caso de Bélgica o Francia. El hecho de que la solicitud de denegación requiera algo más que un mero control de condiciones formales ha llevado a la doctrina a proponer la vuelta a la solución bajo el Convenio de Bruselas, es decir al presidente del Tribunal de Grande Instance: CUNiBERTi, G., op. cit., nota 65, p. 28. El juge de l'exécution podría ser una alternativa eficiente: id. loc.

92 BGBl. 2014 I 890. 
doctrina. Tales críticas no son trasladables necesariamente a otros Estados miembros, en la medida en que se dirigen contra particularidades de las opciones alemanas que podrían no concurrir en otros sistemas: es el caso de la investidura de los Landgericht con la competencia para conocer de las solicitudes de denegación de ejecución, que revoca la todavía vigente atribución a una sala especializada en el Oberlandgericht. Los autores temen que la parte contra quien se solicita la ejecución se aproveche de la falta (presumible) de experiencia de estos órganos ${ }^{93}$.

\subsubsection{Reino Unido e Irlanda ${ }^{94}$}

En el Reino Unido se han aprobado varios Regulations con el fin de facilitar la aplicación del texto europeo a partir del 10 de enero de $2015^{95}$. Los acompaña una Explanatory Note en la que se alude explícitamente a la supresión del exequátur como cambio mayor del Reglamento - que compele por tanto a modificaciones de la ley nacional- En consecuencia se han introducido cambios en la normativa vigente relativa al exequátur (registration), en ocasiones derogándola. Curiosamente no hay mención a la solicitud de denegación de ejecución. La adaptación de las medidas u órdenes desconocidas corresponde al órgano jurisdiccional por demanda de la parte interesada, o de oficio.

Irlanda ha aprobado Regulations en vigor desde el 10 de enero de 2015, a citar como European Union (Civil and Commercial Judgments) Regulations 2015, para asegurar el pleno efecto del Reglamento refundido. Se declara que las decisiones extranjeras con fuerza ejecutiva en origen poseen la misma fuerza y efecto que una decisión irlandesa, y pueden ser ejecutadas como si fueran una resolución de una High Court. La High Court es competente para las solicitudes de denegación de ejecución; cabe que el rechazo sea sólo parcial. La suspensión de la fuerza ejecutiva en origen paraliza la ejecución en Irlanda a petición de la persona ejecutada. La adaptación de las medidas en el sentido del art. 54 del Reglamento requiere una solicitud ex parte al Master de la High Court. No hay referencia a que la decisión a este efecto sea recurrible.

\subsubsection{Polonia}

En Polonia se ha llevado a cabo una modificación del Código de Procedimiento Civil a fin de adaptarlo a diversos Reglamentos europeos, incluyendo

93 Hess, B., op. cit., nota 58, p. 279. Los Landgericht habían sido las autoridades competentes bajo el Convenio de Bruselas; es por ello por lo que la solución adoptada bajo el Reglamento parece un paso atrás: op. ult. cit.; HAU, W., op. cit., nota 49, párr. 14.25 .

94 Hay reformas también en Escocia, en virtud de la Act of Sederunt (Rules of the Court of Session Amendment) [Regulation (EU) No. 1215/2012] 2015, en vigor desde el 7 de febrero. La mayoría de las reformas consisten simplemente en la publicación de formularios uniformes para diversas solicitudes.

95 Civil Jurisdiction and Judgments (Amendment) Regulations 2014. 
el Reglamento Bruselas I bis. Los cambios han entrado en vigor el 10 de enero de 2015. Las nuevas reglas - arts. 1.153 (13) a 1.153 (25) — incorporan los mandatos del Reglamento a propósito de la adaptación de las medidas desconocidas, y los relativos al impacto de los avatares de la resolución extranjera en origen sobre el procedimiento local de ejecución. Los arts. 1.153 (23) y (24) establecen las reglas sobre competencia territorial y recursos cuando la parte ejecutada solicita la denegación de la ejecución en los términos del art. 45 .

\subsection{El caso español}

Aunque no es especialmente tardía, lo cierto es que la reacción española al Reglamento se ha hecho esperar algo más que la de otros legisladores. Con fecha de 31 de julio de 2015 se publicaba oficialmente la Ley 29/2015, de 30 de julio, de cooperación jurídica internacional en material civil ${ }^{96}$, con entrada en vigor veinte días después. Por virtud de su DA $2 .^{a}$ se modifica la LEC con, entre otros extremos, la incorporación de una nueva DF 25. ${ }^{a}$ de Medidas para facilitar la aplicación en España del Reglamento (UE) núm. 1215/2012.

\subsubsection{La necesidad de intervención legislativa}

Antes de la Ley 29/2015 la aplicación del Capítulo III del Reglamento Bruselas I bis en España generaba (en el plano teórico ${ }^{97}$ : no hubo tiempo para verlas en la práctica) una serie de preguntas a la luz de la normativa vigente ${ }^{98}$. Así, por ejemplo, siendo España el país de origen de la decisión a ejecutar cabía dudar acerca de la autoridad a cargo de emitir el certificado en el sentido del art. 53 del Reglamento; una respuesta plausible apuntaba a la misma que dictó la resolución, extendiendo a este caso de la solución de la DF 21. a de la LEC $2000^{99}$.

96 BOE núm. 182, de 31 de julio de 2015.

97 Sobre este punto véase también, con algunas proposiciones distintas, SÁNCHEz LORENZO, S., «El nuevo sistema de reconocimiento y ejecución de resoluciones en el Reglamento (UE) 1215/2012 ("Bruselas I bis")», La Ley Unión Europea, abril 2015, pp. 5-16, esp. pp. 11-12.

98 Algunas se mantienen tras la entrada en vigor de la ley citada. Por poner un ejemplo que además es ya tradicional: la ejecución en España de una decisión dictada en un Estado miembro con posterioridad al 10 de enero de 2015 tendrá lugar conforme a las reglas previstas en los arts. 517 y ss. de la LEC; en este marco, ¿qué juez ostentará la competencia territorial?. El criterio retenido para las decisiones domésticas es funcional, es decir, el mismo tribunal que resolvió sobre el fondo en primera instancia es competente para la ejecución (art. 545.1 de la LEC). Por razones obvias esto no es aplicable al caso de la decisión extranjera. Dos soluciones parecen posibles: la del art. 545.3 de la LEC, que contempla la ejecución basada en títulos distintos, entre otros, de las resoluciones judiciales (ciertamente, la decisión judicial extranjera es un título judicial, pero no asimilable a los nacionales a los efectos de competencia territorial); o la DF vigésimo primera, apartado 5 de la LEC, que establece la competencia para el título ejecutivo europeo.

99 Medidas para facilitar la aplicación en España del Reglamento (CE) núm. 805/2004, del Parlamento Europeo y del Consejo, de 21 de abril, por el que se establece un título ejecutivo europeo para créditos no impugnados. 
Más compleja era la cuestión de la vía procesal para solicitar la denegación de ejecución por los motivos del art. 45 del Reglamento. La ausencia de un procedimiento ad hoc autorizaba imaginar dos soluciones: la primera, integrar la oportunidad dada al deudor en el seno del procedimiento de ejecución mismo; volvemos sobre ella más abajo. La segunda habría sido recurrir al art. 564 de la LEC — conscientes de que se fuerza la norma-. El precepto permite un nuevo proceso de cognición si, después de precluidas las posibilidades de alegación en juicio, se producen hechos o actos distintos de los admitidos como causas de oposición a la ejecución, pero jurídicamente relevantes respecto de los derechos de la parte ejecutante frente al ejecutado o de los deberes del ejecutado para con el ejecutante. Cabría sostener que los argumentos previstos en el art. 45 del Reglamento sólo adquieren relevancia después de precluida la posibilidad de alegarlos en el juicio original: al fin $\mathrm{y}$ al cabo tal relevancia depende del ordenamiento del Estado requerido, y cuál sea éste sólo se conoce una vez recaída la sentencia y hecha la selección del Estado de ejecución por parte del acreedor. El razonamiento no casa, sin embargo, con la tendencia cada vez más extendida en el ámbito de la UE que condiciona el recurso a los motivos de no reconocimiento/ejecución a la imposibilidad de alegarlos en el Estado de origen, reduciendo o directamente privando así de trascendencia a la regulación que al respecto exista en el Estado requerido [art. 34.2 Reglamento Bruselas I, art. 45.1.b) Reglamento Bruselas I bis; recientemente, Sentencia del TJ en el as. C-681/13 a propósito del orden público $\left.{ }^{100}\right]^{101}$. Aparte de ello el art. 564 no indica el procedimiento a seguir; habría aún que identificar «el que corresponda» de conformidad con los criterios al uso (la materia y la cuantía), terminando según el caso en un declarativo ordinario, cauce probablemente excesivo para discutir los motivos del art. 45 Reglamento ${ }^{102}$.

Tampoco la primera opción - canalizar el art. 45 a través del procedimiento previsto para la ejecución ordinaria ${ }^{103}$ — estaba exenta de dudas ${ }^{104}$.

100 ECLI:EU:C:2015:471, núm. 1 del fallo: «Cuando comprueba la eventual existencia de una violación manifiesta del orden público del Estado requerido, el juez de ese Estado debe tener en cuenta que, salvo que concurran circunstancias particulares que dificulten o imposibiliten el ejercicio de los recursos en el Estado miembro de origen, los justiciables deben utilizar en ese Estado miembro todos los recursos disponibles para prevenir tal violación en un nivel superior».

101 A primera vista lo que determina la posibilidad de alegar en el Estado requerido los motivos del art. 34 del Reglamento Bruselas I, o art. 45 el Reglamento Bruselas I bis, es la diligencia o falta de diligencia del deudor en el Estado de origen. La conclusión es la misma en todo caso: las eventuales divergencias en la configuración del orden público, o del derecho de defensa, son indiferentes — como sucede, en una versión más perfecta, en los Reglamentos donde todas las defensas se agotan en el Estado de origen-.

102 Como resultado final de la supresión de un exequátur que era simple y rápido la situación no podría ser más paradójica.

103 Por oposición a la ejecución provisional. Las reglas para este tipo de ejecución en la LEC se adaptan mal (más exactamente: peor que las previstas para la ejecución en general) al Reglamento: la oposición contra la ejecución provisional y contra actuaciones ejecutivas concretas está muy limitada (art. 528); no hay recurso contra el auto que decida sobre la oposición a la ejecución provisional o a medidas ejecutivas concretas (art. 530.4).

104 Algunos aspectos de más sencilla respuesta: el certificado del art. 53 debería ser notificado a la persona contra la que se solicita ejecución antes del despacho de la misma, o como muy tarde con él. El 
El deudor no es oído antes del despacho de ejecución por el juez, al que sigue la providencia en virtud de la cual el secretario judicial adopta las medidas de ejecución específicas. Una vez que recibe la notificación puede oponerse a ambas cosas ${ }^{105}$ : éste sería el momento para argumentar motivos del art. 45 del Reglamento. Ahora bien, de acuerdo con el régimen de ejecución en vigor en España cabe oponerse a la misma por motivos tanto procesales como sustantivos, pero ambos tipos de argumentos son tasados. El art. 556 de la LEC, de hecho, sólo contempla dos motivos sustantivos: el pago y la caducidad de la acción ejecutiva. Algo más flexible es la categoría de los motivos procesales, que enumera el art. 559: está admitido que las causas que allí aparecen permiten acomodar una variedad de argumentos. Sea como fuere, el hecho de que las listas sean cerradas no podría impedir a la persona contra quien se dirige la ejecución esgrimir los motivos del art. 45 del Reglamento refundido. Sin embargo, habría que decidir si éstos son un conjunto independiente de razones contra la ejecución, a sumar a las que ya existen en la LEC, o si por el contrario habría que reconducirlas a las categorías que allí existen; y en este caso, si a la de los motivos sustantivos de oposición, o a la de los procesales $^{106}$. De preferirse la segunda opción una clasificación aceptable podría haber sido entre las causas que conducen a la nulidad radical del despacho de ejecución por carecer el título de los requisitos legales para ser ejecutado (art. 559.3). No obstante hay que recordar que la doctrina española ya había respondido en sentido opuesto a esta posibilidad en relación con el art. 21 del Reglamento sobre el título ejecutivo europeo ${ }^{107}$.

Igualmente incómoda era la cuestión de los recursos. La comunicación de España a la Comisión conforme al art. 75 del Reglamento permite la apelación ante la Audiencia Provincial, el recurso extraordinario por infracción procesal y el recurso de casación ante el Tribunal Supremo. Sin embargo, conforme a las reglas en vigor para la ejecución forzosa actualmente es posible la apelación ante la Audiencia (art. 561.3), pero no un recurso ulterior. Una situación similar (hasta cierto punto) se producía bajo el Reglamento Bruselas I ${ }^{108}$; la primacía del Derecho de la UE obligaba en este caso a admi-

secretario judicial, a quien corresponde la adopción de las medidas de ejecución, sería probablemente el encargado de adaptar las que aparecieran ya en la resolución extranjera y fueran desconocidas en España. El recurso al que se refiere el art. 54 del Reglamento quedaría asegurado por el art. 551.5 de la LEC.

${ }^{105} \mathrm{El}$ ejecutante puede contestar la oposición; el procedimiento es contradictorio en este estadio (art. 529.2 para la ejecución provisional; arts. 559.2 y 560 para la ordinaria).

$106 \mathrm{O}$ incluso a unos u otros en función del motivo considerado entre los previstos en el art. 45 del Reglamento. Merece la pena recordar el tratamiento procesal de los motivos de oposición: los procesales en primer término, y los sustantivos en segundo lugar; una audiencia es posible en relación con estos últimos a instancia de parte.

107 Véase Garcimartín Alférez, F. J., op. cit., nota 76, párr. 125; Ramos Romeu, F., op. cit., nota 29, p. 127, citando a GASCón InCHAUSTI, F.; sobre el art. 22.1 Reglamento sobre el proceso monitorio europeo, García CANo, S., Estudio sobre el proceso monitorio europeo, Cizur Menor, Aranzadi, 2008, párr. 202.

${ }^{108}$ El exequátur toma en España la forma de auto; como regla no cabe el recurso de casación contra los autos, pero ha sido necesario admitirlo en el contexto del Reglamento Bruselas I al estar contemplado en él. 
tir igualmente el recurso ante el TS. El escenario no es el mismo ahora por cuanto el legislador comunitario sólo obliga a habilitar un recurso; aunque con reservas, cabría argumentar que el que se ofrece a mayores no tiene propiamente cobertura en el Derecho de la UE. Sea como fuere, el recurso contra la decisión de segunda instancia a propósito de la denegación de la ejecución sólo podría basarse en los motivos previstos en el art. 45 del Reglamento, y nunca en los de la LEC.

Finalmente, quedaba por determinar la forma de canalizar en el sistema español las opciones que conforme al art. 44.1 del Reglamento se ofrecen a la autoridad competente para la ejecución en caso de solicitud de denegación de la ejecución por razones del art. 45. La limitación del procedimiento a medidas cautelares (art. 44.1.1), así como el condicionamiento de la ejecución a garantías (art. 44.1.2) podrían tener cabida en lo dispuesto en el art. 561.3, segundo párrafo. En cambio, la suspensión del procedimiento (art. 44.1.3) resultaba más difícil de articular: suspender la ejecución es una posibilidad poco frecuente en el caso de la ejecución ordinaria y requiere una previsión legal específica (art. 565 LEC). La oposición de la persona contra la que se solicita la ejecución no la suspende (art. 556.2); si se desestima la oposición y ello se recurre tampoco el recurso paraliza la ejecución (art. 561.3, apdo. 1). La ejecución sí puede ser suspendida en caso de que la oposición se acepte (art. 561.3, apdo. 2).

\subsubsection{La Ley de Cooperación Jurídica Internacional}

La DF segunda de la Ley 29/2015 modifica la LEC incluyendo en ella medidas para facilitar la aplicación del Reglamento Bruselas I bis vía una nueva DF vigésima quinta. La reciente aprobación del texto — simultánea al momento en que esto se escribe- sólo permite hacer una valoración global de urgencia, y sumar algunos comentarios específicos. En relación con lo primero se aprecia que no es un texto elaborado, lo que parece una oportunidad perdida: quedan abiertos aspectos que el operador jurídico necesitará resolver en la práctica, como el de la relación entre el juicio verbal que canaliza los motivos del art. 45 del Reglamento y la oposición que se regula en la LEC, arts. 556 y ss. —en principio, a la luz del diseño previsto en la nueva ley— ${ }^{109}$, correrán en paralelo.

En gran medida la DF remite al propio Reglamento, reproduce su letra o la reformula; en este último supuesto no siempre de manera afortunada. Es el caso del punto 4.6 de la DF en relación con el art. 51 del Reglamento: en éste se contempla la facultad del juez de indicar un plazo para la interposición de recurso en el Estado de origen cuando se pida la suspensión de la ejecución

109 Véase más adelante en este mismo epígrafe. El punto 4.3 de la DF permite al demandante de la denegación de ejecución solicitar las medidas previstas en el art. 44.1 del Reglamento; no hay en cambio una previsión para la situación aludida - la persona contra quien se pide la ejecución se opone a ella por alguna de las razones previstas en la LEC-. 
sobre la base de que tal recurso es aún posible ${ }^{110}$. No ocurre así en la ley; sin embargo, a nuestro juicio es dudoso que esté en manos del legislador nacional eliminar la posibilidad que el Reglamento brinda directamente al órgano jurisdiccional. Tampoco convence la forma en que se alude (punto $6 \mathrm{DF}$ ) a la adaptación prevista en el art. 54 del Reglamento: en éste lo que se adapta son medidas u órdenes de la resolución extranjera, y no esta misma. No se comprende, además, el porqué de una remisión al Reglamento europeo en cuanto a la manera de llevar a cabo la adaptación, cuando habría sido mucho más simple y directo reiterar la idea de encontrar equivalentes y la prohibición de dotar en el foro a la medida extranjera de más efectos que los que tiene en origen; y más útil proporcionar pautas concretas para operar la adaptación.

En puntos del Reglamento en que es precisa una intervención complementaria la DF realiza en ocasiones remisiones internas a disposiciones de la LEC: es lo ocurre al respecto de las medidas cautelares aludidas en el art. 40 (punto $2.4 \mathrm{DF}$ ), y en el art. 54 en lo relativo a los recursos contra la adaptación (punto 6 DF). Estas remisiones son abiertas: por ejemplo, en cuanto al art. 54 lo que se dice es que «cabrán los recursos que la legislación procesal contemple en función del tipo de resolución y de procedimiento de que se trate». Probablemente no cabe una formulación más precisa ante la imposibilidad de predecir qué es lo que necesitará adaptación y dónde se encontrará su equivalente en el seno del ordenamiento español. En el plano conceptual es incluso discutible si el recurso ataca una decisión material (la de adaptar de una determinada forma), o la medida de ejecución misma.

Mayor concreción se ha logrado en cuanto a la notificación del certificado (y en su caso de la resolución extranjera) a que obliga el art. 43 del Reglamento: deberá producirse antes del despacho de ejecución, o con éste (punto $3.1 \mathrm{DF}$ ). El punto 3.2 DF fija el plazo de ejercicio del derecho de pedir la traducción otorgado a la persona contra quien se pide ejecución; la solicitud suspende los plazos de oposición y de contestación a la misma hasta que la traducción se entregue.

De notable importancia es el punto 4 de la DF, acerca de la demanda de denegación de la ejecución en virtud del art. 45 del Reglamento. La tramitación se hará por separado por los cauces del juicio verbal ${ }^{111}$, y no en el marco del procedimiento ejecutivo mismo. Se otorga al demandado en ejecución (actor en la demanda para la denegación) el mismo plazo de oposición que para los motivos contemplados en la LEC: diez días desde la notificación del despacho de ejecución. El procedimiento es contradictorio y puede dar lugar a una vista; termina en sentencia (y no en auto); caben la apelación y los recursos de casación e infracción procesal en las condiciones previstas

110 En realidad el juez del Estado requerido no puede limitar de esta forma el derecho de recurso ofrecido al deudor en el Estado de origen. Lo que sí puede hacer es condicionar la suspensión de su propio procedimiento (el tendente a denegar la ejecución por motivos del art. 45) a que se interponga el recurso en cierto tiempo.

111 La opción no sorprende: la propia LEC simplifica al máximo la tramitación de la oposición a la ejecución y efectúa remisiones a lo dispuesto, precisamente, para el juicio verbal. 
en la LEC. En línea con el art. 46 del Reglamento, la acción se concibe sólo a partir de una solicitud actual de ejecución, es decir, no cabe con carácter preventivo a fin de obtener una declaración sobre la existencia de motivos que evitarían una ejecución futura. En coherencia con esta idea la competencia corresponde al mismo juez que conoce de la ejecución en el Estado requerido.

Para las decisiones españolas a ejecutar en otro Estado el punto 5.1 DF permite entender que se encomienda la emisión del certificado al órgano judicial que se pronuncia sobre el fondo del asunto; pero a la vista de la redacción también cabría entender que corresponde al secretario judicial. No se prevé la contestación de la decisión sobre el certificado o sobre su contenido, ni se contempla la posible rectificación de errores. Tampoco hay referencia a la solicitud del certificado al margen o después de la demanda original, lo que sin duda no significa que no quepa. Es de lamentar que esta ausencia no se haya corregido en las enmiendas al texto.

\section{VALORACIÓN}

\subsection{En singular}

En un mundo dividido en compartimentos jurídicos, donde la ejecución forzosa es monopolio de la autoridad, el procedimiento de exequátur es un puente para posibilitar la ejecución en un Estado de una resolución dictada en otro. En este sentido es un útil a favor de la libre circulación de decisiones. Al mismo tiempo, el exequátur es el momento y lugar para el control de la regularidad de las decisiones extranjeras; en este sentido representa un obstáculo potencial a la aceptación de un producto jurídico fuera de la jurisdicción que lo crea.

En la UE ha prevalecido la segunda percepción del exequátur. En este marco el Capítulo III del Reglamento refundido parece representar un paso adelante hacia la libre circulación de decisiones en la UE. Sin embargo, la impresión es engañosa, y el progreso limitado ${ }^{112}$. De entrada, por lo evidente: el tenor literal del art. 39 del Reglamento refundido reproduce algo que dicen otros instrumentos previos (el art. 5 del Reglamento sobre el título ejecutivo europeo, el art. 19 del Reglamento sobre el procedimiento monitorio, el art. 20 del Reglamento sobre litigios de escasa cuantía, o el art. 17 del Reglamento sobre alimentos); pero mientras éstos eliminan el exequátur en tanto que procedimiento y en tanto que control general de la regularidad de la decisión extranjera, la última función permanece en el Reglamento Bruselas I bis, contradiciendo abiertamente su propia definición de objetivos (Considerando 26).

112 Son muy claras las expresiones de autores como GAScón INCHAUSTI, F., op. cit., nota 18, Sección 5. ${ }^{\text {a }}$ "Beaucoup de bruit pour rien». 
El análisis típico de los obstáculos a la libre circulación de decisiones en la UE se ha centrado, y aún se centra ${ }^{113}$, en la cláusula de orden público y la violación de los derechos del demandado en rebeldía. Sin duda estas amenazas son reales; pero tras el Reglamento refundido el mayor riesgo radica en la complejidad en la ejecución de la resolución extranjera, y su efecto disuasorio. El Reglamento acoge una solución de compromiso con la que cierra un debate; en contrapartida abre otros muchos. La supresión del exequátur otorga el protagonismo al Estado miembro requerido, o Estado de ejecución. Es sabido que la ejecución se lleva a cabo de maneras muy diversas en el seno de la UE. El laconismo, la pobreza, a veces total ausencia de indicaciones o guías en el Reglamento a propósito de aspectos procedimentales es la consecuencia ineludible de la variedad de las reglas locales, que impiden soluciones «one size fits all» y obligan a contar con cada legislador nacional para la perfección del modelo. Eliminando el exequátur el legislador europeo se adentra en un área jurídica altamente compleja y diversa. Al hacerlo pone de manifiesto la necesidad urgente de alcanzar cierto grado de comunidad en este ámbito: la única vía, a nuestro juicio, para hacer real el objetivo de libre circulación en este contexto.

\subsection{La perspectiva global}

En la litigación civil transfronteriza la supresión del exequátur deja el control de las garantías sobre la decisión de cuya circulación se trata en manos del Estado miembro de origen; el sistema es «de ventanilla única» («one-stop shop») ${ }^{114}$. No es así en el Reglamento Bruselas I bis, a pesar de que ya no contempla el exequátur; al mismo tiempo tampoco es sin más clasificable entre los instrumentos que prevén un mecanismo intermedio para el control de la regularidad de las decisiones extranjeras. El Reglamento es singular: es pieza única. Como consecuencia ya no puede ser el referente principal de la red de instrumentos de Derecho procesal civil europeo, como ha ocurrido hasta el momento.

Sucede, sin embargo, que la singularidad empieza a ser rasgo común en la producción legislativa de la UE para la litigación transfronteriza. Por una u otra razón todos los instrumentos son únicos. Ello tiene una lectura en términos de confianza mutua. La confianza recíproca, principio fundacional de la UE, se basa y sustenta al mismo tiempo en una presunción de respeto de los derechos fundamentales y determinados principios básicos por todos los Estados miembros. Ahora bien, el sistema normativo en que esa confianza se traduce está compuesto por textos que en su conjunto revelan asimetría en su alcance: la resistencia a importar el producto jurídico de un Estado miembro en otro es en mayor o menor grado según el instrumento

113 Como muestra, la reciente call for tenders de la Comisión http://ec.europa.eu/justice/newsroom/ contracts/2015_s_104-188196_en.htm.

114 Hess, B., op. cit., nota 33. 
considerado ${ }^{115}$. En función del ámbito material del instrumento europeo en juego cambian la fórmula y grado de reparto de la responsabilidad entre los Estados miembros a la hora de garantizar los derechos fundamentales (y ello pese a que los sistemas judiciales valorados son, en todo caso, los mismos). El panorama conceptual se hace borroso; la práctica se complica ante la dificultad de manejo del conjunto. Menos evidentes pero también relevantes son otras cuestiones, como la de qué Estado debe ocupar la posición de demandado por vulneración de derechos fundamentales ante el TEDH ${ }^{116}$.

\section{RESUMEN}

\section{LA EJECUCIÓN SIN EXEQUÁTUR. REFLEXIONES SOBRE EL REGLAMENTO BRUSSELS I BIS, CAPÍTULO III}

En breve tiempo los tribunales de los Estados miembros de la UE dictarán decisiones judiciales al hilo de acciones civiles o mercantiles incoadas en o después del 10 de enero de 2015; su circulación entre países de la UE estará regida por el Reglamento Bruselas I bis. Desde la propuesta de la Comisión para la reforma del Reglamento Bruselas I en 2010, el dato que más reacciones ha provocado ha sido el de la abolición del exequátur en su vertiente de control de condiciones de cara a la homologación de las decisiones extranjeras. La solución de compromiso que cierra ese debate abre uno nuevo: el de la interactuación de un texto incompleto con las reglas y prácticas nacionales relativas a la ejecución forzosa, intrínsecamente complejas y diferentes entre los Estados miembros. Los operadores jurídicos se verán pronto confrontados en su praxis a dificultades cuyo potencial efecto disuasorio sobre el tráfico transfronterizo no debe ser subestimado.

Palabras claves: litigación civil internacional, materia civil y mercantil, exequátur, ejecución.

\section{ABSTRACT \\ ENFORCEMENT WITHOUT EXEQUATUR: REFLECTIONS ON THE RECAST BRUSSELS I REGULATION CHAPTER III}

EU Member State judgments in civil and commercial matters, consequent to cross-border claims, lodged on or after 10 January 2015, will shortly be recognized and enforced in accordance with Chapter III of the Recast Brussels I Regulation. Since the Commission's proposals for the reform of the Brussels I Regulation in 2010, the most controversial feature of the new system has been the abolition of exequatur as a procedure for validating foreign decisions before they can be declared enforceable. However, the introduction of this solution has given way to new concerns, namely, the conflicts that might arise in the interaction of an incomplete and vague regulation with the inherently complex and highly

115 Unos suprimen el exequátur, otros no. Entre los segundos, el Reglamento (CE) núm. 2201/03 en sus arts. 40 y ss., es ejemplo de un trasvase total del control en la protección de derechos, sustantivos y procesales, al Estado de origen. Bajo determinadas circunstancias otros Reglamentos permiten alegar la irreconciliabilidad de decisiones en el Estado requerido: por ejemplo, el art. 21 del Reglamento (CE) núm. 805/2004, o el art. 22 del Reglamento (CE) núm. 1896/2006; el art. 19 del Reglamento (CE) núm. 4/2009 prevé además un derecho de reexamen a favor del demandado que no haya podido comparecer en el Estado de origen.

116 Véase Hess, B., op. cit., nota 33. 
diverse national rules and practices relating to enforcement in civil and commercial matters. The courts and practitioners will soon be faced with difficulties with potentially negative effects on the further development and promotion of cross-border trade and business should not be underestimated.

Keywords: cross-border civil litigation, civil and commercial matters, exequatur, enforcement.

\section{RÉSUMÉ \\ L'EXÉCUTION SANS EXEQUATUR. RÉFLEXIONS SUR LE CHAPITRE III DU RÈGLEMENT BRUXELLES I BIS}

D'ici peu, les juridictions des États membres de l'UE rendront des décisions, dans des actions judiciaires en matière civile ou commerciale intentées à compter du 10 janvier 2015. Le chapitre III de la refonte du règlement Bruxelles I sera donc applicable à leur exécution. Depuis la proposition de la Commission sur la réforme du règlement Bruxelles I en 2010, la question la plus contestée du nouveau système a été la suppression de l'exequatur en tant qu'outil de control de la régularité des décisions étrangères, préalable à leur exécution dans le for. Ce débat est terminé, mais de nouvelles inquiétudes lui ont succédé. L'interaction du règlement, incomplet et vague, avec les règles et pratiques nationales relatives à l'exécution, intrinsèquement complexes et très diverses, est l'une d'entre elles. Les acteurs juridiques impliqués dans des scénarios transfrontaliers se verront bientôt confrontés dans la pratique aux difficultés juridiques qui en découlent ; leur effet négatif potentiel sur l'objectif de développer et de promouvoir les échanges transfrontaliers dans l'UE ne doit pas être sous-estimé.

Mots-clés: contentieux civils transfrontaliers, matière civile et commerciale, exequatur, exécution. 